\title{
Liquidity Biases in Asset Pricing Tests*
}

\author{
Elena Asparouhova and Hendrik Bessembinder ${ }^{\dagger}$ \\ David Eccles School of Business \\ University of Utah
}

\author{
Ivalina Kalcheva \\ Eller College of Management \\ University of Arizona
}

August 2009

\begin{abstract}
Microstructure noise in security prices biases the results of empirical asset pricing specifications, particularly when security-level explanatory variables are cross-sectionally correlated with the amount of noise. We focus on tests of whether measures of illiquidity, which are likely to be correlated with the noise, are priced in the cross-section of stock returns, and document a significant upward bias in estimated return premia for an array of illiquidity measures in CRSP monthly return data. The upward bias is larger when illiquid securities are included in the sample, but persists even for NYSE/AMEX stocks after decimalization. We introduce a methodological correction to eliminate the biases that simply involves WLS rather than OLS estimation, and find evidence of smaller, but still significant, return premia for illiquidity after implementing the correction.
\end{abstract}

Keywords: bid-ask spreads, illiquidity, asset pricing

JEL classification codes: G1, G2

\footnotetext{
${ }^{*}$ Helpful comments and suggestions were provided by an anonymous referee, Yakov Amihud, Tarun Chordia, Mike Cooper, Wayne Ferson, Kenneth French, Jennifer Huang, Robert Jarrow, Charles Jones, Raymond Kan, Bruce Lehmann, Mike Lemmon, Maureen O'Hara, Marios Panayides, Gideon Saar, Jay Shanken, Avanidhar Subrahmanyam, and Masahiro Watanabe. The authors also benefited from the comments of seminar participants at Cornell University, the University of Arizona, the University of Utah, the University of British Columbia, McGill University, Boston College, Florida International University, ISCTE Business School, Victoria University - Wellington, Fordham University, University of South Carolina, Georgia State University, the University of Hawaii, Georgetown University, Hong Kong University of Science and Technology, Chinese University of Hong Kong, the University of Miami, Toulouse University, National University of Singapore, Singapore Management University, the 2005 FMA Conference, the 2006 Northern Finance Association Meetings, the Fall 2006 NBER Market Microstructure Meeting, the 2009 Asian Finance Association conference, and the Frank Batten Young Scholars Conference. The authors are especially indebted to Lajos Horváth.

${ }^{\dagger}$ Corresponding author: Hendrik Bessembinder, Tel: + 1-801-581-8268, Fax: + 1-801-581-3956, E-mail: finhb@business.utah.edu, Address: David Eccles School of Business, 1645 East Campus Center Drive, University of Utah, Salt Lake City, UT 84112
} 


\title{
Liquidity Biases in Asset Pricing Tests
}

\begin{abstract}
Microstructure noise in security prices biases the results of empirical asset pricing specifications, particularly when security-level explanatory variables are cross-sectionally correlated with the amount of noise. We focus on tests of whether measures of illiquidity, which are likely to be correlated with the noise, are priced in the cross-section of stock returns, and document a significant upward bias in estimated return premia for an array of illiquidity measures in CRSP monthly return data. The upward bias is larger when illiquid securities are included in the sample, but persists even for NYSE/AMEX stocks after decimalization. We introduce a methodological correction to eliminate the biases that simply involves WLS rather than OLS estimation, and find evidence of smaller, but still significant, return premia for illiquidity after implementing the correction.
\end{abstract}




\section{Introduction}

A substantial recent literature considers the effects of microstructure-induced noise for empirical applications in Finance. These papers build on the insight of Blume and Stambaugh (1983) and Black (1986) that observed stock prices can be thought of as the sum of unobservable efficient prices and noise attributable to microstructure effects, including bid-ask spreads. Among the recent studies, Bandi and Russell (2006) develop procedures for estimating separately the volatility of the efficient price and of the microstructure noise, Dennis and Mayhew (2006) examine how microstructure noise affects tests of option pricing models, while Aït-Sahalia, Mykland and Zhang (2005) study how microstructure noise affects the optimal return measurement interval for purposes of volatility estimation.

We extend this literature by studying how microstructure noise affects the results of cross-sectional asset pricing tests. Blume and Stambaugh (1983) show that microstructure noise induces (due to Jensen's inequality) upward bias in measured stock returns, with the bias approximately proportional to the variance of the noise. However, the implications of this bias in measured returns for empirical asset pricing applications do not appear to be widely understood.

We focus in particular on potential biases in tests of whether illiquidity earns a return premium. Theoretical models presented by Amihud and Mendelson (1986), Acharya and Pedersen (2005), and Liu (2006), among others, imply that illiquidity is priced as a security characteristic and/or as a risk factor. The emerging consensus appears to be that illiquidity is indeed associated with a positive return premium. However, we show that standard regression-based tests of whether average returns contain a premium for illiquidity are biased towards finding a premium. 1 1 In particular, we show that almost half of the empirical estimate of the return premium obtained in cross-sectional Fama-MacBeth regressions of monthly returns on effective bid-ask spreads for a sample of NYSE/AMEX stocks is attributable to bias arising from microstructure noise.

While we focus on estimates of illiquidity premia in stock returns, the issues considered here potentially apply to a broad array of empirical asset pricing tests. The bias in estimated regression

\footnotetext{
${ }^{1}$ Brennan and Wang (2009) also observe that mean observed returns are upward biased when prices differ from underlying value. However, they focus on market pricing errors, due for example to investors' underreaction to new information, as the source of the measurement error, while we focus on zero-mean microstructure noise. Their and our analysis both lead to the implication that the estimated return premium associated with illiquidity is likely to be upward biased. In Brennan and Wang the conclusion follows from the observation that mispricing, and hence measured return biases, are likely to be greater for illiquid stocks due to impediments to arbitrage, while in our case the conclusion arises directly from microstructure noise, with or without mispricing.
} 
slope coefficients arises in any case where the explanatory variables are cross-sectionally correlated with the amount of noise in prices. While a non-zero correlation is particularly likely when explanatory variables are empirical measures of illiquidity, it plausibly also arises for an array of other securitylevel measures, including characteristics such as market capitalization, return volatility, measures of asymmetric information, etc.

Microstructure noise in observed prices arises in several ways. Most obviously, the fact that market buy orders are typically completed at an average price that exceeds the true value of the asset, while market sell orders are completed at an average price that is less than the true asset value, implies noise due to "bid-ask bounce.' 22 Noise also arises due to non-synchronous trading, as the last-trade prices commonly used to compute returns need not reflect value as of the close, even in the absence of other frictions. Noise can arise due to orders originating with uninformed traders, as in Black (1986). Further, large orders, including those from institutional investors, are often completed at prices outside the quotations, implying that temporary "price pressure" from large orders contributes to the noise in prices ${ }^{3}$ Also, the use of a discrete pricing grid adds noise to observed security prices, as Fisher, Weaver, and Webb (2009) emphasize.

We consider a set of possible methodological corrections for the biases that arise due to microstructure noise, and show that the biases can be effectively eliminated by use of a simple weighting procedure where each observed return is weighted by (one plus) the observed return on the same security in the prior period. The effectiveness of this correction relies on the same insights as Blume and Stambaugh's (1983) result that the upward bias in average portfolio returns can be greatly reduced by computing portfolio returns on a "buy-and-hold" basis. In each case, the effectiveness of the correction reflects that if the prior trade occurred at a price above the efficient price, then the return measured for the current period is decreased on average, while the weight on the current return is increased, and vice versa. This negative covariance between portfolio weights and return

\footnotetext{
${ }^{2}$ However, the existence of a bid-ask spread does not necessarily imply noise in prices. For example, the model of Glosten and Milgrom (1985) implies that the spread can arise purely due to asymmetric information. In their model trade prices reflect conditional expected values. More generally, "bid-ask bounce" arises from the non-informational components of spreads, including order processing costs, inventory costs, and potential market-making rents. Huang and Stoll (1997) estimate that asymmetric information accounts for less than $10 \%$ of the bid-ask spread in their sample of twenty large-capitalization stocks during 1992.

${ }^{3}$ This price pressure may in part reflect a lack of perfect competition in liquidity provision. See for example, Andrade, Chang, and Seasholes (2008), and Chordia, Roll, and Subrahmanyam (2008) for studies documenting price reversals associated with less-than-perfect liquidity.
} 
measurement errors offsets the original upward return bias attributable to microstructure noise.

To address these issues, we present theory, simulation analysis, and empirical evidence. Theoretical analysis confirms that parameters estimated in virtually any cross-sectional regression that uses observed returns as the dependent variable are biased and inconsistent, when prices contain noise. Estimated return premia for illiquidity in particular are likely to be upward biased. We also demonstrate that the proposed methodological correction eliminates the biases attributable to noise in prices, in large samples. The simulations verify that plausible quantities of microstructure noise are associated with an economically meaningful bias in estimated return premia for illiquidity. The simulations are also used to evaluate the effect of excluding illiquid securities on the bias and the power of the tests, and to assess the rate at which the bias is eliminated by the proposed correction as the sample size is increased.

Finally, we report the results of a broad empirical investigation of relations between stock returns and liquidity, with and without corrections for microstructure bias, using CRSP monthly return data from 1926 to 2006. Pástor and Stambaugh (2003) note that "liquidity is a broad and elusive concept that generally denotes the ability to trade large quantities quickly, at low cost, and without moving the price." We therefore examine an array of illiquidity measures broadly representative of those widely used in the literature, including six measures of (il)liquidity as stock characteristics, as well as two measures of systematic (il)liquidity risk (attributable to Pástor and Stambaugh (2003) and Hasbrouck (2009), respectively), while controlling for estimated market return beta, and betas on the Fama and French (1993) "HML" and "SMB" factors.

Comparison of return premium estimates with and without corrections for microstructure noise reveals economically large and statistically significant biases in estimated premia on all six (il)liquidity characteristics, and to a lesser extent on the estimated premium for factor loadings on the two systematic (il)liquidity risk measures. For example, the return premium on the effective bid-ask spread that is estimated in cross-sectional monthly return regressions for exchange-listed stocks from 1926 to 2006 is $0.18 \%$ with correction for microstructure bias, compared to an estimate of $0.33 \%$ without correction. The differential of $0.15 \%$ per month is attributable to microstructure noise, and is highly significant $(t$-statistic $=15.9)$. Notably, however, estimated coefficients on each of the illiquidity characteristics remains significant after correcting for microstructure noise. The results 
therefore support the conclusion that illiquidity does indeed earn a return premium, though not as large as estimated without correcting for microstructure noise.

Recent studies, e.g. Bessembinder (2003), have reported that quoted bid-ask spreads on U.S. equity markets are quite narrow, particularly subsequent to the 2001 shift from fractional to decimal pricing. This evidence might be viewed as suggestive that measurement errors attributable to microstructure noise are a minor concern. However, our empirical analysis shows a significant upward bias in estimated illiquidity premia even in monthly return data from 2001 to 2006, for both Nasdaq and Exchange-listed stocks. Further, researchers have and will continue to study asset pricing and liquidity in non-U.S. markets, which generally have wider spreads 4 That the upward bias remains significant even in recent data characterized by relatively narrow spreads reflects that microstructure noise arises not only from quoted spreads, but also from the price impacts of large orders, a lack of perfect competition in liquidity provision, and other sources of friction.

This paper is organized as follows. Section [I] summarizes a number of related papers, with emphasis on studies addressing the relation between average returns and illiquidity. Section III demonstrates that standard cross-sectional regressions of security returns on security attributes or risk measures provide biased and inconsistent parameter estimates when prices contain noise. Section IV considers a set of possible methodological corrections and presents our recommended correction, which mitigates the biases induced by microstructure noise and can be easily implemented in any database. Section $\mathrm{V}$ reports the results of a set of simulation exercises that verify significant upward biases in estimates of the return premium for illiquidity given plausible amounts of microstructure noise, and that allow assessment of the effect of excluding securities with wide bid-ask spreads from the empirical analysis and of the rate at which the proposed correction eliminates the bias as sample size increases. Section VI reports the results of our empirical analysis of relations between stock returns, (il)liquidity measures, and estimated betas, with and without corrections for microstructure noise. Section VII discusses possible extensions of the analysis and concludes.

\footnotetext{
${ }^{4}$ For example, Table 2 in Jain (2001) indicates bid-ask spreads that average $6.10 \%$ as recently as year 2000 for a sample of forty seven non-U.S. markets that includes both developed and developing economies.
} 


\section{The Literature on Liquidity Premia}

The relation between average returns and measures of liquidity has been the subject of considerable research interest. Amihud and Mendelson (1986), Acharya and Pedersen (2005), and Liu (2006), among others, present theoretical models implying that illiquidity is priced as a security characteristic and/or a risk factor. In contrast, models presented by Constantinides (1986), Heaton and Lucas (1996), and Vayanos (1998) imply that the potential effects of illiquidity on prices should not be substantial, because agents will adjust their portfolio trading frequencies to mitigate illiquidity costs. However, Jang, Koo, Liu and Loewenstein (2007) show that Constantinides' conclusion depends crucially on the assumption of a constant investment opportunity set.

Numerous papers have addressed the issue empirically. Amihud and Mendelson (1986) report evidence consistent with their theoretical predictions for NYSE-listed stocks 5 However, Eleswarapu and Reinganum (1993) find a statistically significant relation between average return and bid-ask spread for NYSE stocks only in January. Chalmers and Kadlec (1998) examine the amortized spread (which incorporates also investors' holding periods), for NYSE and AMEX stocks and find that the relation between average returns and illiquidity is stronger for amortized than for unamortized spreads. Brennan and Subrahmanyam (1996) report that stock returns are cross-sectionally related to trading activity, which proxies for liquidity. Eleswarapu (1997) tests the Amihud and Mendelson (1986) model using Nasdaq stocks, finding stronger support for the model as compared to earlier results for NYSElisted stocks.

In addition to the studies that focus on illiquidity as a potentially-priced stock characteristic, Pástor and Stambaugh (2003) and Acharya and Pedersen (2005) provide evidence that systematic liquidity risk affects average returns. Korajczyk and Sadka (2008) provide an integrated analysis indicating that both systematic liquidity risk and the Amihud (2002) illiquidity measure are priced in the cross-section of stock returns. Fujimoto and Watanabe (2008) use a regime-shifting model to document that liquidity risk varies over time and that the estimated liquidity risk premium is larger at times of high return sensitivities to an aggregate liquidity factor.

The emerging consensus, as summarized for example by Amihud, Mendelson and Pedersen (2005),

\footnotetext{
${ }^{5}$ It should be noted that Amihud and Mendelson were aware that bias in measured returns attibutable to bid-ask spreads could bias their empirical estimates. On page 245 they discuss implementing a correction attributable to Blume and Stambaugh, and note that they continued to obtain estimates supporting their hypotheses.
} 
appears to be that illiquidity and illiquidity risk do affect average asset returns. However, our analysis shows that existing empirical estimates of the premium for illiquidity are biased in favor of finding a premium.

\section{The Bias in Cross-Sectional OLS Estimates}

\section{A. The Cross-Sectional Regression Setting}

We consider the effects of microstructure noise on coefficient estimates obtained in cross-sectional OLS regressions of observed security returns on a vector of firm characteristics and/or risk measures. Throughout, we focus on gross one-period returns, the ratio of security price to prior period price. Let $\tilde{\mathbf{X}}_{\mathbf{t}}=\left(\mathbf{1}, \mathbf{X}_{\mathbf{t}}\right)$, where $\mathbf{1}$ denotes an $N$-dimensional vector of ones and $\mathbf{X}_{\mathbf{t}}=\left(\mathbf{X}_{\mathbf{1 t}}, \mathbf{X}_{\mathbf{2}}, \ldots, \mathbf{X}_{\mathbf{N t}}\right)^{\prime}$, denotes an $N \times(K-1)$ matrix, where the $n$-th row is the $K-1$ characteristics or risk measures (assumed stationary) for stock $n$ at time t, for stocks, $n=1,2, \ldots N$.

Letting true parameters be denoted by $\tilde{\boldsymbol{\beta}}=\left(\alpha, \boldsymbol{\beta}^{\prime}\right)^{\prime}$, where $\alpha$ is a scalar and $\boldsymbol{\beta}$ is a $K-1$ vector, the time $t$ true gross return of stock $n$ is given by:

$$
R_{n t}=\tilde{\mathbf{X}}_{\mathbf{n t}} \tilde{\boldsymbol{\beta}}+\epsilon_{n t}=\alpha+\mathbf{X}_{\mathbf{n t}} \boldsymbol{\beta}+\epsilon_{n t},
$$

where $\epsilon_{n t}$ is a white noise random error term If $\mathbf{R}_{\mathbf{t}}=\left(R_{1 t}, R_{2 t}, \ldots, R_{N t}\right)^{\prime}$ and $\boldsymbol{\epsilon}_{\mathbf{t}}=$ $\left(\epsilon_{1 t}, \epsilon_{2 t}, \ldots, \epsilon_{N t}\right)^{\prime}$, we can write the return equation for stocks $1, \ldots, N$ in matrix form as:

$$
\mathbf{R}_{\mathbf{t}}=\tilde{\mathbf{X}}_{\mathbf{t}} \tilde{\boldsymbol{\beta}}=\alpha \mathbf{1}+\mathbf{X}_{\mathbf{t}} \boldsymbol{\beta}+\boldsymbol{\epsilon}_{\mathbf{t}}
$$

\section{B. Microstructure Noise and OLS Coefficient Estimates}

Following Blume and Stambaugh (1983), observed prices differ from true prices due to microstructure noise, including the non-informational component of the bid-ask spread. As a consequence,

\footnotetext{
${ }^{6}$ In the Appendix we relax this assumption to allow for serial correlation in the true return process.
} 
returns are measured with error. In particular, the observed (gross) return for stock $n$ at time $t$ is: $]^{7}$

$$
R_{n t}^{0}=R_{n t} \frac{1+\delta_{n t}}{1+\delta_{n t-1}} \approx R_{n t}\left(1+\delta_{n t}\right)\left(1-\delta_{n t-1}+\delta_{n t-1}^{2}\right)
$$

where $\delta_{n t}$ is zero-mean noise in the time $t$ observation of security $n$ 's price. We assume that $\delta_{n t}=\sigma_{n} \delta_{n t}^{0}$, where $\delta_{n t}^{0} \sim(0,1)$, so that $\sigma_{n}^{2}$ is the variance of $\delta_{n t}$, and that $\delta_{n t}^{0} \perp\left(\delta_{m \tau}^{0}, \mathbf{X}_{\mathbf{m} \boldsymbol{\tau}}, \sigma_{n}^{2}, \sigma_{m}^{2}\right)$ for any $n \neq m$ or $t \neq \tau$. We also assume that the parameters $\sigma_{n}^{2}$ are draws from a common distribution across stocks, i.e., $\sigma_{n}^{2} \sim\left(\sigma^{2}, \Sigma\right)$ for all $n=1,2, \ldots, N$.

Note that we have followed Blume and Stambaugh (1983) in assuming for tractability that the zero-mean noise in each security's prices is independently and identically distributed. The assumption that the noise is uncorrelated across time may not be accurate in actual data. For example, large orders are often split into smaller orders executed sequentially, which may imply positive serial dependence in noise (e.g. due to a sequence of trades at the ask or bid). However, the relevance of any serial dependence in $\delta_{n t}$ depends in part on the return measurement interval. Monthly returns, for example, would not be affected by serial dependence in the $\delta_{n t}$ that persisted for intervals less than a month. Of course, daily or shorter horizon returns would more likely be affected.

We also follow Bandi and Russell (2006) in assuming for tractability that the $\delta_{n t}$ are uncorrelated across the $\mathrm{N}$ securities. This assumption potentially contrasts with the empirical evidence of commonality in illiquidity. However, the available evidence indicates such commonality is not large. Chordia, Roll, and Subrahmanyam (2000) report adjusted r-squared statistics for cross-sectional regressions of firm-level on marketwide illiquidity measures that are uniformly less than two percent. Similarly, Hasbrouck and Seppi (2001) report that the first principal component explains less than eight percent of the variation in signed order flow across stocks. These results suggest that relaxing the orthogonality assumptions is likely to have little effect on the results of our analysis, particularly when applied to the monthly return interval commonly used for empirical asset pricing applications.

In what follows, unless noted otherwise, for any random variable the expectation operator $E(\cdot)$ is used to denote the cross-sectional expectation $E(\cdot \mid t)$. Similarly, we use $\operatorname{Cov}(\cdot, \cdot)$ to denote $\operatorname{Cov}(\cdot, \cdot \mid t)$. All derivations are provided in the Appendix.

\footnotetext{
${ }^{7}$ This is expression (4) from from Blume and Stambaugh (1983), with $R_{i, t}=1+r_{i, t}$ and $R_{i, t}^{o}=1+r_{i, t}^{o}$, and also uses the second-order approximation in Blume and Stambaugh footnote 6. Our expressions for the bias in the OLS estimate are therefore also second-order approximations.
} 
Proposition 1. The OLS regression of time $t$ observed gross returns $\mathbf{R}_{\mathbf{t}}^{\mathbf{o}}$ onto $\tilde{\mathbf{X}}_{\mathbf{t}}$ produces biased and inconsistent coefficient estimates. In particular, the estimated vector of slope coefficients converges in probability to:

$$
\boldsymbol{\beta}_{\mathrm{OLS}}=(\alpha \boldsymbol{\lambda}+\boldsymbol{\Gamma} \boldsymbol{\beta})
$$

and the intercept estimate converges in probability to:

$$
\alpha_{O L S}=\alpha\left(-\boldsymbol{\mu}_{\mathbf{X}} \boldsymbol{\lambda}+\sigma^{2}+1\right)+\left(-\boldsymbol{\mu}_{\mathbf{X}} \boldsymbol{\Gamma}+\left(1+\sigma^{2}\right) \boldsymbol{\mu}_{\mathbf{X}}+\operatorname{Cov}\left(\sigma_{n}^{2}, \mathbf{X}_{\mathbf{n t}}\right)\right) \boldsymbol{\beta},
$$

where

$$
\begin{aligned}
\boldsymbol{\mu}_{\mathbf{X}} & =E\left(\mathbf{X}_{\mathbf{n t}}\right) \\
\mathbf{V}_{\mathbf{X}} & =\operatorname{Var}\left(\mathbf{X}_{\mathbf{n t}}\right)\left(=\operatorname{Cov}\left(\mathbf{X}_{\mathbf{n t}}, \mathbf{X}_{\mathbf{n t}}\right)\right), \\
\boldsymbol{\Gamma} & =\mathbf{I}+\mathbf{V}_{\mathbf{X}}{ }^{-1} \operatorname{Cov}\left(\sigma_{n}^{2} \mathbf{X}_{\mathbf{n t}}, \mathbf{X}_{\mathbf{n t}}\right), \text { where } \mathbf{I} \text { is the } K \times K \text { identity matrix, } \\
\boldsymbol{\lambda} & =\left[\mathbf{V}_{\mathbf{X}}{ }^{-1} \operatorname{Cov}\left(\sigma_{n}^{2}, \mathbf{X}_{\mathbf{n t}}^{\prime}\right)\right] .
\end{aligned}
$$

Corollary 1. When the set independent variables includes only $\mathbf{1}$, the vector of ones, i.e. when computing the sample gross mean return, the result converges to $\alpha\left(\sigma^{2}+1\right)$. The upward bias in the estimate of the cross sectional mean return is $\alpha \sigma^{2}$.

Corollary 2. If $\sigma_{n}^{2} \perp \mathbf{X}_{\mathbf{n t}}$, the OLS slope coefficient vector estimate converges to $\boldsymbol{\beta}\left(1+\sigma^{2}\right)$, i.e., the bias in the slope coefficients vector is $\sigma^{2} \boldsymbol{\beta}$, and the OLS intercept converges to $\alpha\left(\sigma^{2}+1\right)$, i.e., the bias in the intercept is equal to $\alpha \sigma^{2}$.

\section{B.1. Discussion}

Blume and Stambaugh (1983) show that microstructure noise in security prices induces an upward bias in the mean return observed for each security, $n$, approximately equal to $\sigma_{n}^{2}$, the variance of the noise in stock $n$ prices. Corollary 1 demonstrates the corresponding result for the cross-sectional mean observed gross return at time $t$, which is an upward biased estimate of the true cross-sectional mean 
return. The bias is proportional to $\sigma^{2}$, the mean across securities of the $\sigma_{n}^{2} \mathrm{~g}^{8}$

Proposition 1 shows that slope coefficients obtained by OLS regression of observed returns on security specific attributes are biased when prices contain random noise, unless (i) the true slope coefficients, $\boldsymbol{\beta}$, are a vector of zeros, and (ii) $\boldsymbol{\lambda}=0$, which requires that the regressors are uncorrelated with the amount of microstructure noise, i.e. $\operatorname{Cov}\left(\sigma_{n}^{2}, \mathbf{X}_{\mathbf{n t}}\right)=0$. Corollary 2 considers the case when the latter condition is met. Then, the effect of microstructure noise is to magnify the true relation, as the bias in the OLS slope coefficients is the product of the true coefficient vector $\boldsymbol{\beta}$, and the cross sectional mean amount of noise, $\sigma^{2}$.

In addition, correlation across securities between the amount of noise $\sigma_{n}^{2}$ and observations on the regressors $\mathbf{X}_{\mathbf{n t}}$ induces bias in the estimated slope coefficients. Note that $\boldsymbol{\lambda}$ can be interpreted simply as the vector of slope coefficients obtained in a cross-sectional regression of $\sigma_{n}^{2}$ on the firm specific variables, $\mathbf{X}_{\mathbf{n t}}$. The slope coefficients obtained in the OLS regression of observed returns on security attributes are biased when the elements of $\boldsymbol{\lambda}$ are non-zero. If the true slope coefficients are zero, the bias is necessarily in the same direction as the signs of the respective elements of the $\boldsymbol{\lambda}$ vector. The elements of $\boldsymbol{\lambda}$ are particularly likely to be non-zero for explanatory variables that are measures of (il)liquidity, such as bid-ask spreads, trading activity, etc. However, it is also plausible that the elements of $\boldsymbol{\lambda}$ could be non-zero for many security-level measures that are not direct measures of illiquidity, including market capitalization, measured return volatility, measures of asymmetric information (such as the "PIN" measure introduced by Easley, Kiefer, O'Hara and Paperman (1996)), analyst following, etc., each of which is which is likely to vary systematically across securities whose prices contain more versus less noise.

\section{B.2. How large is the bias? A back-of-the-envelope calculation}

To obtain a preliminary assessment of the possible magnitude of the bias attributable to noise in prices, assume that true returns are zero-mean random variables, implying $\boldsymbol{\beta}=0$ and $\alpha=1$, and that the bias in the slope coefficient vector is exactly $\boldsymbol{\lambda}$. Further, assume for simplicity that the bid-ask

\footnotetext{
${ }^{8}$ To illustrate the existence of the bias in single-period mean returns, assume that the true value of every security is 10.0 at both time $t$ and $t-1$, but that due to microstructure noise observed prices are either 9.8 or 10.2 , with equal probability. The observed time $t$ return for each security can therefore be zero (if consecutive prices are either 9.8 or 10.2 , combined probability 0.5 ), $-3.922 \%$ (if the time $t-1$ price is 10.2 and the time $t$ price is 9.8 , probability 0.25 ), or $4.082 \%$ (if the time $t-1$ price is 9.8 and the time $t$ price is 10.2 , probability 0.25 ). Averaged over a large number of securities the mean observed return is $0.04 \%$, even though the mean true return is zero.
} 
spread is the only source of noise in prices. Then, the effective bid-ask spread for trade $t$ in stock $n$ is $2 *\left|\delta_{n, t}\right|$. Assume further that $\delta_{n, t}$ has a uniform distribution over the interval $\left[-S_{n}, S_{n}\right]$. This implies that average proportional effective spread for stock $n$ is $S_{n}$, and that $\sigma_{n}^{2}=\frac{S_{n}^{2}}{3}$. Finally, assume that the only explanatory variable in the cross-sectional return regression is $S_{n}$.

Given these assumptions, the bias in the estimated return premium associated with the effective spread is $\boldsymbol{\lambda}=\frac{\operatorname{Cov}\left(\sigma_{n}^{2}, S_{n}\right)}{\operatorname{Var}\left(S_{n}\right)}=\frac{\operatorname{Cov}\left(S_{n}^{2}, S_{n}\right)}{3 * \operatorname{Var}\left(S_{n}\right)}$. Note that for any random variable $U$ with standard deviation $\sigma_{U}$ and skewness $s_{U}$,

$$
\frac{\operatorname{Cov}\left(U^{2}, U\right)}{\operatorname{Var}(U)}=2 E(U)+s_{U} \sigma_{U} 9
$$

In particular, if the variable $U$ is symmetrically distributed, we have $\frac{\operatorname{Cov}\left(U^{2}, U\right)}{\operatorname{Var}(U)}=2 E(U)$. Therefore, if in addition to the prior simplifying assumptions, the cross-sectional distribution of spreads is symmetric, the bias in the OLS regression slope coefficient can be stated as $\boldsymbol{\lambda}=\frac{2 * S}{3}$, where $S=E\left(S_{n}\right)$ is the cross-sectional mean effective proportional bid-ask spread. Under these assumptions the bias in the estimated slope coefficient on the effective spread is necessarily positive, equal to two-thirds the average proportional effective spread in the sample.

If sample bid-ask spreads are moderate, so is the bias in the estimated return premium for illiquidity, given these simplifying assumptions. For example, if the sample average effective proportional spread is .015, the upward bias is .01. The bias in the estimated return premium for a .01 increase in the spread (e.g. from $1 \%$ to $2 \%$ ) would be just .01*.01 $=.01 \%$. Note, though, that even this modest bias could become relevant if the researcher annualizes estimates. The magnitude of the bias is, assuming serial independence of the noise, invariant to the horizon over which returns are measured. If the estimate is obtained in daily data and the researcher annualizes by multiplying by 250 , the bias in the estimated effect on annual returns of a $1 \%$ increase in spreads becomes $2.5 \%$ per year.

Many databases used to assess empirical asset pricing models will include securities with larger average spreads. For example, Chalmers and Kadlec report an average spread of $2.4 \%$ for a sample of NYSE/AMEX stocks drawn from the 1980s. Jain (2001) reports bid-ask spreads that average $6.10 \%$

\footnotetext{
${ }^{9}$ To see this, let $\mu_{i}$ denote the $i$-th uncentered moment of the random variable $U$. $\operatorname{Var}(U)=\mu_{2}-\mu_{1}^{2}$. Given skewness of $s_{U}$, we have $\mu_{3}=3 \mu_{1} \mu_{2}-2 \mu_{1}^{3}+s_{U} \sigma_{U}^{3}$. Therefore $\operatorname{Cov}\left(U^{2}, U\right)=\mu_{3}-\mu_{1} \mu_{2}=2 \mu_{1}\left(\mu_{2}-\mu_{1}^{2}\right)+s_{U} \sigma_{U}^{3}=\left(2 \mu_{1}+s_{U} \sigma_{U}\right) \operatorname{Var}(U)$.
} 
as recently as year 2000 for a sample of forty seven non-U.S. markets. Fortin, Grube, and Joy (1989) report that bid-ask spreads for Nasdaq stocks averaged $9.9 \%$ during a sample drawn from the 1980s and $13.0 \%$ during a sample drawn from the 1970 s.

Focusing on the Fortin et al. data for 1980s Nasdaq stocks, the upward bias in the estimated slope coefficient relating returns to spreads would be .0663 , given the simplifications assumed here. The average spread for the smallest quintile of securities by market capitalization in Fortin et. al's 1980s sample is $23.7 \%$. Thus, the bias in the estimated return premium for stocks in the smallest quintile relative to stocks with a spread near zero would be $.0663^{*} .237=1.57 \%$ per period, or about $19 \%$ per year if annualized from monthly data.

We conclude from these simple calculations that the bias in estimated return premia attributable to noise in security prices is potentially large enough to be economically meaningful. The actual bias will differ from the benchmark developed here due to the simplifying assumptions used. Indeed, the empirical estimate of the upward bias in the estimated return premium on effective spreads for NYSE/AMEX stocks that we report in Section VI is larger than implied by these calculations. This likely reflects that actual prices include noise from sources other than bid-ask spreads. Also, as Equation (4) indicates, positive skewness in the cross-sectional distribution of spreads implies a larger bias in the estimated relation between returns and spreads, ceteris paribus.

\section{Potential Solutions}

We next consider a set of possible methodological solutions that researchers might adopt to mitigate the influence of microstructure noise on asset pricing tests. These include the use of quotation midpoint returns, adjusting returns for the estimated upward bias, the use of continuously compounded returns, as well as a return-weighting procedure that we believe will be effective in the broadest set of circumstances.

\section{A. Quotation Midpoint Returns}

If the quote midpoint always reflects the efficient value of the security, then a simple empirical solution is to compute returns from quote midpoints instead of from reported closing prices. However, theory suggests that the quote midpoint may not always equal the efficient value. Some models (e.g. 
Ho and Stoll (1980)) imply that liquidity providers will move quotation midpoints away from asset value in order to manage inventory. Further, as Fisher, Weaver, and Webb (2009) emphasize, the use of a discrete price grid prevents quote midpoints from revealing efficient values. They report simulation-based evidence indicating that microstructure noise can lead to biases in computed stock price indices, and that the bias is reduced but not eliminated by the use of quote midpoints instead of trade prices.

Moreover, reliance on quote midpoints to compute returns may be limited by data availability. Quotation data for stocks listed on the NYSE and Nasdaq is available from the Trade and Quote (TAQ) database from 1993 onward, and daily closing quotes for Nasdaq NMS stocks are available from 1983 forward. Shanken and Zhou (2007) note that a lack of statistical power may be an important issue in asset pricing applications, and the available time series of mid-point returns may not be sufficient for many applications.

\section{B. Adjust Closing Returns for Microstructure Noise}

As noted, Blume and Stambaugh (1983) show that that upward bias in the observed return for stock $n$ is $\sigma_{n}^{2}$. A simple adjustment would be to deduct an estimate of this quantity from each return observation. As an example, Blume and Stambaugh (1983) show (their expression (7)) that if bidask spreads are the sole source of microstructure noise, securities trade each period, and the bid-ask spread is constant over time for a given stock, then $\sigma_{n}^{2}$ can be estimated as $\frac{S_{n}^{2}}{4}$. Alternately, given the assumptions of the previous section, including that $\delta_{n, t}$ has a uniform distribution, $\sigma_{n}^{2}$ can be

estimated as $\frac{S_{n}^{2}}{3}$. However, neither set of simplifying assumptions is likely to be accurately reflected in actual data.

Alternately, if time series of both trade and quotation data are available then, assuming that the quote midpoint equals the true security value at the time of the last trade, $\delta_{n, t}$ can be measured for security $n$ on day $t$ as the difference between the last trade price and the quote midpoint, and $\sigma_{n}^{2}$ can be estimated from a time series of observations for a given security. However, the effectiveness of this approach is limited both by data availability and by the implicit assumption that the quote midpoint is the true asset value. Alternately, advanced econometric methods such as the model presented by Bandi and Russell (2006) may allow for direct estimation of $\sigma_{n}^{2}$. 


\section{The Use of Continuously Compounded Returns}

As Blume and Stambaugh (1983, footnote 9) observe, the upward bias in mean returns stemming from microstructure noise does not exist under reasonable assumptions if the focus is on continuously compounded rather than holding period returns, suggesting that biases in empirical asset pricing applications can be avoided by using continuously compounded rather than simple returns. However, this solution is appropriate only if the asset pricing theory being tested makes predictions regarding mean continuously compounded returns, as in Merton (1971). It is problematic when testing theories, e.g. the discrete time Capital Asset Pricing Model or the Arbitrage Pricing Theory, whose implications regard mean holding period returns. Ferson and Korajczyk (1995) articulate several reasons that it is not appropriate to use continuously compounded returns when testing discrete-time asset pricing models, including: (1) wealth depends on the simple return to the investors' portfolios, (2) continuously compounded portfolio returns are not the portfolio-weighted averages of the securities' continuously compounded returns, and most importantly (3) the mean continuously compounded return is less than the mean simple return, with the differential increasing in the return variance. Further, Dorfleitner (2003) has documented that betas estimated from continuously compounded returns can differ dramatically from betas defined in simple returns.

\section{Weighting by Lagged Gross Returns}

Blume and Stambaugh (1983) describe how the upward bias in average returns for a portfolio of stocks can be substantially eliminated by computing portfolio returns on a "buy-and-hold" basis. Here, we describe a simple and easily-implemented modification to standard cross-sectional regression techniques that provides consistent estimates of equal-weighted mean returns and of cross-sectional asset pricing parameters.

The "buy-and-hold" methods discussed by Blume and Stambaugh are equivalent to computing portfolio returns as a weighted average of observed returns, where the weights are chosen to induce a negative correlation between weights and observed returns. While Blume and Stambaugh rely directly on observed prior period share prices as weights (see their expression (9)), such a negative correlation can be induced by a number of weighting methods that depend on observed prior period prices, including the selection of weights proportional to observed prior period market capitalization (value- 
weighting). In each case, the negative correlation is induced by the use of the prior trade price to define both the weight and the current period return: if the prior trade occurred at a price greater than true value, the current period return is decreased on average, while the return weight is increased, and vice versa. This negative correlation offsets the original upward return bias attributable to microstructure noise. In contrast, as Blume and Stambaugh note, equal-weighting of observed security returns does not induce a negative covariance between observed returns and portfolio weights (which are constant), and as a result does not reduce bias.

However, in many applications researchers are indeed interested in measuring mean returns on an equal, rather than price or value-weighted basis. Similarly, in cross-sectional asset pricing specifications researchers typically place equal weight on the return data for each firm, rather than increasing weights for securities with high share prices or larger market capitalizations.

Indeed, Blume and Stambaugh's empirical implementation of their "buy-and-hold" approach is based on portfolios characterized by equal capital investments in each stock at the beginning of each year, with positions held constant for the remainder of the year. (Equivalently, portfolio weights are selected based on the gross observed return from the end of the prior year through the prior period). However, as Blume and Stambaugh (1983) acknowledge (their footnote 16), in this implementation the bias in portfolio returns is not mitigated during the first period of the year 10 This limitation is particularly relevant if researchers rely on monthly returns, with portfolios formed on a calendar year basis, in which case January returns would not be corrected 11

We propose to modify the Blume and Stambaugh (1983) correction by selecting weights based on prior-period observed gross (one-plus) returns. While the label "buy-and-hold" may not readily apply, the use of the prior period observed price to compute both the prior return and the current return induces the requisite negative correlation between weights and observed returns. Our specific recommendation is that the cross-sectional regression of observed security returns on a constant and firm-level variables be estimated by weighted-least-squares (WLS) instead of OLS, with weights defined as prior period gross returns. This method is easy to implement, and allows for correction of each period's returns (except the first observation of the sample), including the first period of each year.

\footnotetext{
${ }^{10}$ Blume and Stambaugh implement their correction in daily data, where the effect of failing to correct returns for microstructure noise for a single period per year is likely to be minuscule.

${ }^{11}$ As noted, Eleswarapu and Reinganum (1993) find a significant relation between bid-ask spreads and average returns for NYSE stocks only during the month of January.
} 
Most importantly, it allows for consistent estimation of equal-weighted mean portfolio returns and of cross-sectional asset pricing parameters, as shown in the next section 12

\section{D.1. The Effectiveness of Return-Weighting in Cross-Sectional Regressions}

We next demonstrate the effectiveness of the proposed return-weighting correction for crosssectional asset pricing tests that estimate the relation between security returns and security-level characteristics and/or risk measures ${ }^{13}$

Proposition 2. Let $\boldsymbol{\beta}_{\mathbf{W L S}}=\left(\tilde{\mathbf{X}}_{\mathbf{t}}^{\prime} \mathbf{W}_{\mathbf{t}} \tilde{\mathbf{X}}_{\mathbf{t}}\right)^{-1}\left(\tilde{\mathbf{X}}_{\mathbf{t}}^{\prime} \mathbf{W}_{\mathbf{t}} \mathbf{R}_{\mathbf{t}}^{\mathbf{0}}\right)$, where the weighting matrix, $\mathbf{W}_{\mathbf{t}}$, is the diagonal matrix with $\operatorname{diag}\left(\mathbf{W}_{\mathbf{t}}\right)=\mathbf{R}_{\mathbf{t}-\mathbf{1}}$. Then $\boldsymbol{\beta}_{\mathbf{W L S}}$ is a consistent estimator of $\tilde{\boldsymbol{\beta}}$ and $\frac{1}{\sqrt{N}}\left(\boldsymbol{\beta}_{\mathbf{W L S}}-\right.$ $\tilde{\boldsymbol{\beta}}) \longrightarrow N\left[0, \mathbf{A}(\tilde{\boldsymbol{\beta}})^{-1} \mathbf{B}(\tilde{\boldsymbol{\beta}}) \mathbf{A}(\tilde{\boldsymbol{\beta}})^{-1}\right]$. Here, $\mathbf{A}(\tilde{\boldsymbol{\beta}})=\lim E\left(\left.\frac{1}{N} \frac{\partial^{2} S_{N}}{\partial \mathbf{b} \partial \mathbf{b}^{\prime}}\right|_{\mathbf{b}=\tilde{\boldsymbol{\beta}}}\right)$, and $\mathbf{B}(\tilde{\boldsymbol{\beta}})=\lim E\left(\frac{1}{N}\left(\left.\frac{\partial S_{N}}{\partial \mathbf{b}}\right|_{\mathbf{b}=\tilde{\boldsymbol{\beta}}}\right.\right.$ )$\left.\times\left(\left.\frac{\partial S_{N}}{\partial \mathbf{b}^{\prime}}\right|_{\mathbf{b}=\tilde{\boldsymbol{\beta}}}\right)\right)$, where $S_{N}(\mathbf{b})=\sum_{n=1}^{N} R_{n t-1}^{0}\left(R_{n t}^{0}-\tilde{\mathbf{X}}_{\mathbf{n t}} \mathbf{b}\right)^{2}$.

Corollary 3. When the independent variables includes only $\mathbf{1}$, the vector of ones, WLS estimation produces a consistent estimate of the (cross-sectional) mean gross return.

Proposition 2 establishes that estimation of the cross-sectional regression by weighted least squares, with prior period gross (one plus) returns used as weights, leads to consistent estimates of the true parameter vector. Blume and Stambaugh (1983) note that bias reduction obtained by the use of buyand-hold methods can be interpreted as a diversification effect, and is complete only when the number of securities, $N$, becomes large. Consistent with this reasoning, the proof establishes consistency of the weighted least squares estimates as the number of securities becomes large, not unbiasedness in

\footnotetext{
${ }^{12}$ We thank Charles Jones for conversations that led us to consider weighting by prior period gross returns as a correction for microstructure noise in prices. Applied to the computation of mean portfolio returns, our method is equivalent to assessing period t returns to a portfolio that was equal-weighted at time $t-2$. Note that Fisher and Weaver (1992) develop, and Fisher, Weaver, and Webb (2009) implement, a method for asymptotically correcting measured returns on equal-weighted stock indices that is algebraically equivalent to weighting by gross returns. However, neither Fisher and Weaver nor Blume and Stambaugh consider methods for consistent estimation of regression slope coefficients in the presence of microstructure noise, as we do.

${ }^{13}$ Although the focus here is on cross-sectional regressions, we have also proven that weighting by the lagged gross return produces consistent parameter estimates in stock-by-stock time series regressions. The proof is available from the authors on request.
} 
small samples 14

Researchers commonly follow Fama and MacBeth (1973) in estimating separate cross-sectional regressions for each period, $t$, with the final coefficient estimates comprised of time series means of period by period estimates. Proposition 2 establishes the consistency and asymptotic normality of the period $t$ estimate. These characteristics will clearly carry over to the time series mean of period-byperiod estimates 15

As a special case, Corollary 3 demonstrates that the cross-sectional mean return obtained when weighting by prior period gross returns is a consistent estimate of the true cross-sectional mean return. The intuition for the effectiveness of the return-weighting procedure is that conveyed by Blume and Stambaugh: the use of prior period observed returns induces negative covariation between observed returns and weights that offsets the original bias.

\section{D.2. Cross-Sectional Regressions Using Portfolio Returns}

As noted, our focus is on cross-sectional regressions of security returns on security-level explanatory variables. However, many researchers conduct empirical asset pricing tests by regressing portfolio returns on portfolio-level explanatory variables 4 If portfolio returns are computed as an equalweighted average of observed component security returns, the bias in the mean portfolio return attributable to microstructure noise in prices is simply the average of the biases in the individual security returns, as Blume and Stambaugh show. The ensuing cross-sectional regression of portfolio returns on portfolio-level explanatory variables is then likely to be afflicted by biases of the same type as documented in Proposition 1 for firm-level regressions.

\footnotetext{
${ }^{14}$ We have followed Bandi and Russell (2006) and many others in assuming that true returns are serially independent. In the appendix, we consider the case where true returns are autocorrelated. This analysis indicates that the regression slope coefficients obtained by WLS estimation remain consistent when true returns are autocorrelated, if returns are independent of the explanatory variables (implying the vector $\boldsymbol{\beta}$ is zero). The slope coefficients are also consistent if the security specific return autocorrelation parameter is independent of the regressors and the amount of noise. The slope coefficients are inconsistent when neither of these independence conditions are met. However, simulation evidence (not reported) indicates that the remaining bias in the slope coefficients is too small to detect unless both the degree of serial correlation is severe (e.g. autocorrelation coefficients in excess of 0.90 ) and the elements of the $\boldsymbol{\beta}$ vector are implausibly large. In contrast, serial correlation in true returns can significantly bias estimates of the WLS regression intercept, i.e. estimates of the cross-sectional mean return. Note that the same limitation applies to the empirical buy-and-hold procedure implemented by Blume and Stambaugh (1983).

${ }^{15}$ Peterson (2009) discusses a number of issues related to estimation of the correct standard error of the time series mean. These issues are not addressed by the correction we introduce.

${ }^{16}$ Ang, Liu, and Schwartz (2009) provide an analysis of the relative benefits of individual-security versus portfolio-level analysis in empirical asset pricing applications.
} 
However, if portfolio returns are constructed as a weighted average of component security returns, with weights that rely on the prior period observed price, then the induced negative covariance between weights and returns mitigates the bias in the portfolio return. Examples include weighting by the prior period share price itself, prior period market capitalization, or by prior period gross return ${ }^{17}$ If the bias is eliminated from portfolio returns, OLS estimation of the cross-sectional regression will yield consistent parameter estimates, in the absence of other specification problems.

\section{Exploring the Microstructure-Induced Biases: Simulation Evi- dence}

The analysis in Section III shows that microstructure noise induces bias in estimated return premia for illiquidity or other security characteristics, while the analysis in Section IV] shows that the bias can be eliminated in large samples if each security return is weighted by the prior period gross return. While we implement this technique in actual stock return data in Section VI, we first report on the results of a set of simulations. We use the simulation approach, where true parameters are known, to assess the tradeoff between bias reduction and statistical power when relatively illiquid securities are excluded from the analysis. Also, given that our proposed return-weighting demonstrates consistency, but not unbiasedness, we rely on the simulation to assess the rate at which the bias is mitigated as the sample size is increased, given plausible quantities of microstructure noise. The simulations are repeated 250 times, which allows consideration of both the mean and the variability of the estimated return premia.

Since most asset pricing studies are conducted in monthly returns, we focus on parameters selected to roughly correspond to monthly stock return data. 18 We construct simulated true and observed returns for 1500 stocks. Construction of the simulated return data is detailed in the Appendix. In brief, the simulated true returns conform to the CAPM, with a beta premium of $0.8 \%$ per month. With one exception noted below, true returns contain no premium for illiquidity. Observed returns

\footnotetext{
${ }^{17}$ Note that weighting returns during each month of a calendar year by market capitalization as of the end of the prior year will not mitigate the bias in portfolio returns, except during the first period of the year.

${ }^{18}$ However, the issues are likely to be more important in daily data. While the absolute bias is independent of the return measurement interval, the bias relative to true mean returns is larger for high frequency observations. CRSP has recently made available daily returns for NYSE stocks dating to December 1925. We anticipate that the issues discussed here will be particularly important in potential asset pricing studies that rely on this data.
} 
are computed from true returns as in Eq.(3), assuming that bid-ask spreads are the sole source of microstructure noise. Bid-ask spread parameters are assigned to simulated securities to ensure that mean spreads by sample decile match those reported by Chalmers and Kadlec (1998) for NYSE and AMEX stocks and by Fortin, Grube, and Joy (1989) for Nasdaq stocks. We simulate two research scenarios. In the first, asset pricing tests are conducted with spreads reflective of NYSE and AMEX securities, while in the second tests are conducted in a sample comprised of $50 \%$ of stocks with NYSE/AMEX spreads and 50\% with Nasdaq spreads.

We report results obtained with the widely-used Fama and MacBeth (1973) methodology, where return premia are estimated as time series averages of regression coefficients obtained in period-byperiod cross-sectional regressions of returns on beta estimates and security characteristics. To be consistent with actual practice, we use portfolio grouping techniques to estimate betas. Following Fama and French (1992), we assign stocks to 100 portfolios (ten estimated beta by ten measured spread). Return premia on beta and bid-ask spreads are estimated by cross-sectional regressions of individual security returns on estimated portfolio betas and individual security spreads.

\section{A. Results of Simulated Fama-MacBeth Tests}

Column (1) of Table If Panel A reports results obtained when simulated true percentage returns are regressed on percentage bid-ask spreads and betas estimated from true returns, while Columns (2) and (3) report results using simulated observed percentage returns, with spreads calibrated to NYSE/AMEX and NYSE/AMEX/Nasdaq levels, respectively (Column (4) will be discussed in Section $\mathrm{V} / \mathrm{C}$. Results in Column (1) indicate that standard methods reveal true parameters on average in the absence of microstructure noise. In particular, the mean estimated beta premium of $0.798 \%$ lies within one standard error of the true parameter of $0.80 \%$, and the mean estimated spread premium of -0.0008 is also close to the true parameter of zero, and is statistically insignificant.

Reflecting the theory presented in Section III, the estimated premium for illiquidity obtained when using observed returns in the OLS regressions is significantly upward biased by microstructure noise. Focusing first on results reported in Column (2) of Table I. Panel A, the estimated spread premium averages about 0.031 per month, with an average $t$-statistic across simulations of 7.67 . The inclusion of less-liquid Nasdaq securities in the simulated sample (Column (3)) increases the upward bias on the 
spread premium to 0.088 per month, with an average $t$-statistic of almost twenty six. Since spreads earn no premium in our simulated true returns, the estimated premium is entirely illusory. The bias in the estimate of the spread premium of 0.088 in the simulated NYSE/AMEX/Nasdaq sample is somewhat larger than predicted based on the "back-of-the-envelope calculations" in Section III. This reflects positive skewness in the distribution of effective spread estimates used for the simulation, which as noted, increases the bias.

\section{B. Can the Bias be Avoided by Excluding Illiquid Securities?}

A natural question is whether the bias arising from microstructure noise in prices can be avoided by focusing on more liquid samples, for example by restricting the analysis to more recent data, or by omitting stocks with large spreads or low share prices. To shed some light on this issue we conduct simulations where wide-spread securities are eliminated from the analysis. However, to illustrate a potential tradeoff between bias and statistical power, we construct for the simulations reported in this subsection only, a new set of true returns where stocks earn a spread premium equal to $\gamma_{s}\left(S_{n}-S\right)$, where as before $S_{n}$ is the average proportional spread for stock $n$ and $S$ is the mean spread in the simulated sample, and $\gamma_{s}$ is a spread premium, set equal to $\gamma_{s}=.06$. The premium of .06 per month implies that a security with a $10 \%$ average spread would earn a true return premium of $0.6 \%$ per month or about $7.2 \%$ per year.

Column (1) of Table I, Panel B reproduces results reported in Panel A, Column (3), except that the estimated spread premium has been increased due to the inclusion of the .06 actual spread premium now contained in the data. The mean estimated spread premium of .147 exceeds the true premium of .06 by 870 times the standard error (across the 250 simulations) of the mean. Column (2) of Panel B reports results when $10 \%$ of stocks have been excluded from the sample, Column (3) reports results when $20 \%$ of stocks are excluded, etc. Stocks are excluded sequentially, beginning with those with the widest bid-ask spreads. The results indicate that the bias in the spread premium declines rapidly as the widest-spread stocks are excluded from the analysis. When only the widest-spread decile is excluded the estimated spread premium declines from 0.147 to 0.102 . Excluding the second widestspread decile further reduces the estimated spread premium to 0.088. When the analysis includes only the narrowest-spread decile the estimated premium of 0.063 is only slightly greater than the true 
parameter of 0.060 .

However, statistical power to detect the true positive relation between returns and spreads also declines rapidly as securities are omitted from the analysis. This reduction in power reflects both the smaller sample size and the reduced cross-sectional variation in spreads. The tradeoff between reduced bias and reduced power is illustrated vividly when focusing on results obtained when $80 \%$ of sample stocks are excluded. In this case the average estimated spread premium across the 250 simulations is 0.069 , which reflects only a moderate upward bias. At the same time, the average $t$-statistic for the hypothesis that the spread premium equals zero is only 1.13 across the 250 simulations. In 201 of the 250 individual simulations the $t$-statistic on the spread is less than 1.96, implying that a researcher would have failed to detect the actual positive spread premium at conventional significance levels. We therefore conclude that the upward bias in the estimated spread premium can indeed be greatly reduced by excluding illiquid securities, but at a cost in statistical power such that the researcher may not be able to detect a true positive illiquidity premium, if it exists.

\section{How Large a Sample is Required to Fully Eliminate the Bias?}

To verify that the return weighting approach is indeed effective in finite samples in eliminating bias in the estimated relation between returns and illiquidity obtained, we conduct simulations where the cross-sectional regressions are estimated by WLS rather than OLS, with one plus the prior period observed return used as the weighting variable. Spreads are calibrated to NYSE/AMEX/Nasdaq levels. Results reported on Table If Panel A, Column (4) verify the effectiveness of the correction. The mean estimated spread premium using WLS is just 0.0001, as compared to a mean estimate of 0.088 obtained using OLS. Evidently the simulated sample size of $N=1500$ securities is sufficiently large for the large-sample proof of the effectiveness of the WLS correction provided in Section IV to apply.

We next assess the effectiveness of the WLS correction in smaller samples. To do so, we assign spread parameters and create 250 sets of simulated returns for 1500 securities as previously described, and then select $N$ of these securities at random for inclusion in asset pricing tests. Panel $\mathrm{C}$ of Table

I reports results for several different samples sizes. Column (1) of Panel C reports results for a very small simulated sample, with only $N=60$ securities. Even in this small sample the correction is quite 
effective, as the mean spread premium estimated by WLS is 0.0056, less than one tenth as large as the mean OLS estimate of 0.0779. However, the mean WLS estimate exceeds the true parameter of zero by almost 15 times the standard error of the mean, indicating that upward bias persists in the small sample.

The mean spread premium estimated by WLS declines monotonically as the sample size increases, to 0.0029 with $N=120$ securities, 0.0016 with $N=180$ securities, 0.0012 with $N=240$ securities, etc. While these estimates remain upward biased (lying more than two standard errors from zero), the estimates are quite small relative to the mean OLS estimates, which remain in the vicinity of .08. When the sample size is increased to $N=600$ securities the mean spread premium estimated by WLS is essentially zero in both economic (point estimate of only 0.0002 per month) and statistical (the mean estimate is approximately one standard error from the true parameter of zero) terms.

We conclude from this simulation analysis that the proposed WLS correction can eliminate most of the bias arising from microstructure noise even in samples as small as $N=60$ securities, and for practical purposes eliminates all of the bias with sample sizes in the vicinity of $N=600$ securities or larger, given realistic quantities of microstructure noise.

\section{Empirical Evidence on the Pricing of Illiquidity}

We next report on the results of a series of asset pricing tests implemented in monthly CRSP return data, with and without corrections for microstructure noise. We report on tests of whether CRSP stock returns are cross-sectionally related to six stock-specific measures of (il)liquidity, and to betas estimated on two measures of systematic (il)liquidity risk, while controlling for market return betas, betas on the Fama and French "HML" and "SMB" factors, and firm size. The intent is to assess the extent to which microstructure noise biases OLS coefficient estimates for explanatory variables representative of those commonly used in the literature, and the sensitivity of those estimates to our proposed WLS correction.

\section{A. Data Description and Empirical Methods}

We obtain from CRSP monthly returns on common stocks (CRSP share code 10 or 11) for NYSElisted firms over the interval 1926 to 2006, AMEX-listed firms from 1962 to 2006, and Nasdaq-listed 
firms from 1983 to 2006. The exclusion of Nasdaq firms before 1983 reflects the lack of trading volume data before that date. Overall "market" returns and returns to the Fama and French (1993) "HML" and "SMB" factors are obtained from Kenneth French's website. Several empirical (il)liquidity measures, generally representative of those broadly employed in the literature, are obtained from Joel Hasbrouck's website. The construction of these variables is described in detail in Hasbrouck (2009) and in documents on Hasbrouck's website. The measures are computed from daily data, and compiled for each stock on an annual basis. The measures include:

- Illiq - the Amihud (2002) illiquidity measure; constructed for each stock/year as 1000 multiplied by the square root of the annual mean of the daily ratio of absolute return to dollar volume (variable I2 variable in the Hasbrouck dataset).

- Amivest - the Amivest measure; constructed for each stock/year as the 0.001 multiplied by the square root of the annual mean of the daily ratio of volume to absolute return (variable L2 in the Hasbrouck dataset).

- Effective Spread - effective bid-ask half spread; constructed for each stock/year as the annual mean of daily estimates obtained by the Bayesian "Gibbs Sampler" method (variable $c_{-} B M A$ in the Hasbrouck dataset multiplied by 100).

- Logvol - the natural logarithm of the annual trading volume for each stock in thousands of shares.

- Pctzero - percent zero; the proportion of the days in the year with no price change, for each stock. This measure was introduced by Lesmond, Ogden, and Trzcinka (1999). The model presented in that paper was based on the reasoning that investors are deterred from trading when transactions costs are high, and that effective trading costs can be inferred from the frequency of days without trade.

- Pctnotrade - we also construct a variable measuring the proportion of days in the year with zero trading volume.

Note that Amivest and Logvol can be viewed as measures of liquidity, while the other four variables should be viewed as measures of illiquidity. Amihud (2002) observes that marketwide averages of illiquidity measures demonstrate very substantial variation from year to year. His analysis is based on 
a standardized illiquidity measure constructed as the illiquidity measure for stock $n$ in year $t$ divided by the market average illiquidity measure for year $t$. We implement a similar standardization for Illiq, Amivest, and Logvol. Also following Amihud (2002), we exclude stocks from the sample for any year where CRSP data is available for less than 200 days.

In addition to these six measures of (il)liquidity as stock characteristics, we incorporate in the analysis estimated betas on two measures of marketwide (il)liquidity risk. Hasbrouck (2009) uses the Bayesian Gibbs Sampler method to construct a measure of innovations in a latent factor common to effective trading costs for all stocks, which he denotes $z u$. We also obtain from CRSP the variable ps_innov, which is a measure of innovations in marketwide liquidity based on equation (8) in Pástor and Stambaugh (2003).

The Pástor-Stambaugh measure is available from 1962 to 2005, while the the Hasbrouck measure is available for our full 1926-2006 sample period. We therefore rely mainly on the Hasbrouck zu measure, but also report some results obtained using ps_innov as the measure of market wide liquidity risk. Note that ps_innov decreases with marketwide illiquidity (the measure is more negative during illiquid periods) while $z u$ increases with illiquidity (the measure is more positive during periods of illiquidity). Therefore, the theory advanced by Pástor and Stambaugh (2003) and Acharya and Pedersen (2005) implies a positive return premium on betas estimated with respect to ps_innov and a negative return premium on betas estimated with respect to $z u$.

We implement Fama-MacBeth asset pricing tests with these data by monthly regressions of individual stock returns on stock characteristics and estimated betas assigned to each stock based on portfolio membership for the year. Following Hasbrouck (2009), we form 25 portfolios for each year, based on information available at the end of the prior year. Portfolios are formed based on independent quintile rankings on effective spread and individual stock beta estimates obtained from the prior five years' data. Monthly portfolio returns are created as the cross-sectional average of component stock returns in excess of the risk free interest rate. Portfolio betas are estimated by a full-sample time-series regression of portfolio returns on the overall market return $\left(\beta_{r m}\right)$, the FamaFrench "HML" and "SMB" factors $\left(\beta_{h m l}\right.$ and $\left.\beta_{s m b}\right)$, and either of the two marketwide liquidity factors $\left(\beta_{p s}\right.$ or $\left.\beta_{z u}\right)$, and the resulting beta estimates are assigned to each stock contained in that portfolio by year. 
Cross-sectional regressions of individual stock excess returns on beta estimates and security characteristics are estimated on a monthly basis, and final return premia estimates are the timeseries means of the monthly estimates. T-statistics incorporate the Shanken (1992) correction for errors-in-variables. As Hasbrouck (2009) notes, the two-stage procedure with Shanken corrections is asymptotically equivalent to single stage GMM estimation. The security characteristics included in any month's regression are measured based on data from the prior year, and thus could be known to market participants.

\section{B. Summary Statistics}

Table II reports summary statistics, including mean, median, and standard deviation for variables used in the analysis. Panel A reports the summary statistics for NYSE/AMEX (1926 - 2006) and Nasdaq (1983 - 2006) sample, while Panel B reports results by subperiod 19

While we report these summary statistics mainly to facilitate interpretation of the economic significance of the estimated regression coefficients reported in subsequent sections, a few observations are noteworthy. First, the Bayesian Gibbs sampler estimates of effective half spreads in the 2001-2006 (post-decimalization) sample are indeed lower than in earlier periods, but are still substantial. For Nasdaq stocks, the mean effective half spread exceeds 1.0\% post-decimalization, and for NYSE/AMEX stocks the mean effective half spread is $0.60 \%$. Also, Pctnotrade and Pctzero are quite distinct variables. For example, the cross-sectional median of Pctzero for NYSE/AMEX stocks is 18.2, compared to a cross-sectional median of Pctnotrade is only 0.4, indicating that zero return days are far more frequent than zero volume days. Finally, cross-sectional means substantially exceed medians for several illiquidity measures, including Illiq, Effective Spread, Pctnotrade and Pctzero. This indicates right-skewed distributions of illiquidity, suggesting that a relatively few highly-illiquid stocks may be quite influential. As noted in Section III, positive skewness increases the bias in the estimated illiquidity premia, ceteris paribus.

\footnotetext{
${ }^{19}$ As mentioned, Illiq, Amivest, and Logvol measures have been standardized.
} 


\section{Empirical Results for NYSE-AMEX Stocks}

Table III] Panel A reports results of Fama-MacBeth regressions of stock returns on $\beta_{r m}$ and the six (il)liquidity characteristics in turn, using all available NYSE and AMEX-listed stocks. Results are obtained based on OLS regressions, and WLS regressions, with one plus the prior period security return used as the weighting variable. The column labeled "DIF" reports the time series mean of the difference between the monthly OLS and WLS estimates, and quantifies the bias in the return premium estimate attributable to microstructure noise.

Notably, this analysis reveals significant bias away from zero in the estimated return premium for illiquidity, for all six measures. The bias is very significant in statistical terms, with absolute t-statistics ranging from 9.40 for Illiq measure to 15.9 for the Effective Spread measure. The bias is also significant in economic terms, as point estimates indicate the bias is about a quarter to a third of the original OLS point estimates. For example, the upward bias in the estimated premium on the Illiq measure is $0.125 \%$, while the standard deviation of the Illiq measure is 1.45 . A researcher estimating the change in the expected return for a two standard deviation change in the Illiq measure would overestimate the relation by $2^{*} 1.45^{*} 0.125=0.36 \%$ per month, or approximately $4.4 \%$ per year.

The results on Table III, Panel A indicate upward bias in the estimated return premium associated with the effective bid-ask spread of 0.144. Had the explanatory variable been full rather than half spreads, the empirical estimate would have been 0.072. The average effective half (full) spread for this sample of NYSE-AMEX stocks is .0088 (.0176). Applying the 'back-of-the-envelope' calculations from Section B.2, the implied bias is two thirds the mean full spread, or .0117. That the actual empirical estimate of the upward bias, 0.072, substantially exceeds the estimate implied by the backof-the-envelope calculations likely reflects that microstructure noise arises from sources in addition to bid-ask spreads, and that the distribution of spreads is right-skewed rather than symmetric.

Notably, the WLS estimates of (il)liquidity premia remain significant for all six measures, indicating higher average returns for stocks with greater illiquidity measures and lower stock returns for stocks with greater liquidity measures. The $t$-statistics on the bias-adjusted premia estimates range from 2.36 for the Amivest measure to 4.65 for the Pctnotrade measure. The bias-adjusted coefficient estimates remain substantive in economic terms as well. For example, the bias-adjusted return premium estimate on the Illiq measure is $0.230 \%$, implying that the average monthly return differential for a two standard 
deviation change in the Illiq measure is $2^{*} 1.45^{*} 0.230=0.67 \%$ per month, or approximately $8.0 \%$ per year.

This analysis therefore supports the conclusions that (1) illiquidity is indeed priced as a stock characteristic, but (2) microstructure noise imparts a significant bias into the estimates of the illiquidity premium that can be corrected by the return weighting method recommended here. In contrast to the significant estimates of illiquidity premia, the estimated premium on $\beta_{r m}$ is, consistent with recent research, insignificant in each specification.

The six (il)liquidity characteristics considered here are likely to be highly correlated with each other. Table III, Panel B reports the results of a "horse race" where all six measures are included in each month's cross-sectional regression. Of the six measures, only the Illiq measure retains statistical significance (WLS $t$-statistic $=2.42$ ). We therefore focus on the Illiq stock characteristic for the remainder of our analysis.

Table IV] reports results obtained when additional explanatory variables are included in the monthly cross-sectional regression specifications for NYSE-AMEX stocks over the 1926 to 2006 period. Specification (1) reproduces results for the Illiq measure from Table III for comparison. Specification (2) adds $\beta_{z u}$ to assess whether systematic illiquidity risk earns a return premium, conditional on illiquidity as a stock characteristic. While the results do indicate a significant upward bias attributable to microstructure noise, the estimated premium for $\beta_{z u}$ does not differ significantly from zero in either the OLS or the WLS specification.

Specifications (3) to (6) of Table IV report as sensitivity tests results obtained when various combinations of additional variables, including Logcap, $\beta_{s m b}$ and $\beta_{h m l}$ are added to the cross-sectional regressions. The key insight is that the following conclusions are not affected by the inclusion of any combination of these additional variables: (i) estimated premia on the Illiq measure and $\beta_{z u}$ are upward biased by microstructure noise, (ii) systematic liquidity risk does not earn a return premium, and (iii) the Illiq measure does earn a return premium.

We next turn to a more detailed analysis of estimated return premia for systematic (il)liquidity risk. Panel A of Table $\mathrm{V}$ reports results obtained in cross-sectional Fama-MacBeth regressions that include betas estimated with respect to the Pástor and Stambaugh (2003) ps_innov measure over the 1962 to 2005 period, while Panel B of TableVVreports results obtained over the 1926 to 2006 period in 
specifications that instead include betas estimated with respect to the Hasbrouck (2009) zu measure of marketwide illiquidity. Specification (1) of each Panel includes the same stocks as prior analyses, while in specifications (2), (3), and (4) we follow Pástor and Stambaugh (2003) in excluding stocks with share prices below $\$ 5$ and above $\$ 1000$. Focusing first on Column (4) of Panel A, the results indicate a positive and significant return premium on the systematic liquidity risk measure $\beta_{p s}$, based both on OLS estimation $(t$-statistic $=2.66)$ and WLS estimation $(t$-statistic $=2.52)$. Consistent with that finding, results reported in Column (4) of Panel B indicate a negative and significant return premium on the systematic illiquidity risk measure $\beta_{z u}$, in both OLS estimation $(t$-statistic $=-2.68)$ and WLS estimation $(t$-statistic $=-2.25)$. That is, when relying on a research design broadly similar to that of Pástor and Stambaugh (2003) we obtain results consistent with theirs, as the estimates indicate a significant return premium for systematic liquidity risk.

However, results with regard to systematic liquidity risk are weakened somewhat when the crosssectional regression also includes betas estimated with respect to the Fama-French factors and stocks' market capitalization: the WLS $t$-statistic on $\beta_{p s}$ in specification (3) is reduced to 1.87. Note, however, that the WLS $t$-statistic on $\beta_{z u}$ (Panel B) in specification (3) remains statistically significant, possibly reflecting improved statistical power due to the longer sample interval over which the $z u$ measure is available.

Specifications (1) and (2) reported on Table $\mathrm{V}$ provide results when the Illiq measure is also included in the cross-sectional regressions. The results continue to indicate that Illiq earns a premium as a stock characteristic. However, the results also indicate that Illiq as a stock characteristic subsumes the explanatory power of systematic (il)liquidity risk: estimated return premia on both $\beta_{p s}$ (Panel A) and $\beta_{z u}$ (Panel B) become statistically insignificant in both specifications (1) and (2), with absolute $t$-statistics obtained by WLS that range from 0.63 to 1.48 .

Turning to the issue of the bias in estimated return premia attributable to microstructure noise, point estimates reported on Table $\mathrm{V}$ paint a mixed picture. Each estimate continues to indicate upward bias in the estimated return premium on Illiq, which can be understood based on the high likelihood of positive cross-sectional correlation between the Illiq measure and the unobservable microstructure noise that is the source of the upward bias in returns. In contrast, it is difficult to anticipate ex ante the likely direction or magnitude of the bias in the estimated premium for systematic risk attributable 
to microstructure noise: the actual bias will depend on the partial correlation between unobservable microstructure noise and the specific systematic risk measure employed, and this correlation itself depends on the additional explanatory variables included in the regression as well as the set of securities included. Point estimates indicate unstable bias in estimates of return premia for systematic liquidity risk. In particular, the sign of the bias in the return premium estimated in specification (1) is the opposite of the sign of the bias estimated in specification (4), for both $\beta_{p s}$ (Panel A) and $\beta_{z u}$ (Panel B). In short, case-by-case empirical analysis is likely necessary to establish the direction and magnitude of the bias in estimates of the premium on systematic liquidity risk.

\section{C.1. Subsample Estimates for NYSE-AMEX Stocks}

We next turn to the question of whether the conclusions obtained in the full sample regarding the existence of bias and the magnitude of bias-adjusted return premia are stable across time. Table VI reports results obtained for NYSE and AMEX stocks for three subperiods: Panel A contains results for the 1926 to 1962 period, Panel B reports outcomes from 1963 to 2000 data, while Panel C reports outcomes using data from 2001 to 2006. During the first subperiod the CRSP data pertains only to NYSE-listed stocks. The second and third subperiods contain both NYSE and AMEX-listed stocks. The last subperiod is the post-decimalization sample, which is of particular interest since it allows assessment of whether biases attributable to illiquidity remain an issue in light of the narrow post-decimalization bid-ask spreads. Results are reported for a specification where only the Illiq measure and $\beta_{r m}$ are included in the cross-sectional regressions, and when betas on the Hasbrouck (2009) systematic illiquidity risk and the Fama-French factors are included, along with stocks' market capitalization.

Focusing on results obtained when returns are regressed on $\beta_{r m}$ and the Illiq measure, the illiquidity premium estimated without a correction for microstructure noise is upward biased in all three subperiods, including the post-decimalization sample $(t$-statistic $=3.25$ in Column DIF). The finding that microstructure noise continues to impart a significant bias in the estimate of the return premium for illiquidity despite the narrowing of bid-ask spreads after decimalization suggests strongly that the microstructure-based noise in stock prices is not limited to the effect of trades occurring at posted bid and ask quotes. However, the results are consistent with the reasoning that the bias has 
decreased over time: point estimates of the upward bias in the illiquidity premium estimate are $0.16 \%$ for the 1926-1962 sample, $0.10 \%$ for the 1963 to 2000 sample, and $0.07 \%$ for the 2001-2006 sample. Notably, the bias-corrected results indicate a positive and significant return premium on the Illiq measure for all three subperiods. Point estimates are quite stable over the three subperiods, equaling $0.24 \%, 0.22 \%$, and $0.25 \%$, respectively.

\section{Empirical Results for Nasdaq Stocks}

Finally, to assess whether the key findings regarding biases attributable to microstructure noise and the pricing of illiquidity are robust to alternate market structures, we report some results obtained in CRSP monthly return data for Nasdaq-listed stocks. However, as this analysis is limited to the 1983 to 2006 period by a lack of volume data necessary to construct the Illiq measure for earlier years, we report only an abbreviated set of results for Nasdaq stocks. Panel A of Table VII reports results using the full Nasdaq sample. The key results are that, consistent with the NYSE/AMEX evidence, the estimated coefficient on the Illiq measure is significantly upward biased $(t$-statistic $=3.09$, Column DIF for the second regression specification), but the Illiq measure is indeed associated with a positive return premium even after bias adjustment $(t$-statistic $=4.11$, Column WLS for the second regression specification) 20

Panels B and C of Table VII report results for Nasdaq-listed stocks separately for the 19832000 and 2001-2006 subperiods, respectively. The key observation is that, consistent with results for NYSE/AMEX stocks, the upward bias in the Illiq measure remains positive and significant in the post-decimalization data, at least in the simpler specification that excludes additional control variables $(t$-statistic $=3.91)$.

To summarize, the empirical evidence for NYSE/AMEX and Nasdaq stocks provides strong evidence that estimates of the premium for illiquidity as a stock characteristic obtained in monthly returns are upward biased by microstructure-based measurement errors in prices. This bias exists

\footnotetext{
${ }^{20}$ Amihud (2002) and Pástor and Stambaugh (2003) exclude stocks with share prices below five dollars from their studies. When we implement this exclusion in the Nasdaq sample (results not tabulated) the upward bias in the estimated illiquidity premium is indeed reduced, from $0.15 \%$ to $0.02 \%$. However, neither the OLS nor the WLS estimate of the premium on the Illiq measure remain significant. That is, consistent with the implications of the simulation analysis reported on Table [1] the exclusion of illiquid securities reduces the bias attributable to microstructure noise, but at a cost in statistical power such that the positive bias-adjusted relation between returns and illiquidity is not detected. A similar exclusion in the NYSE/AMEX data also reduces bias and the estimated illiquidity premium, but a positive relation is still detected.
} 
across subperiods, including the post-decimalization sample. Microstructure noise also imparts bias to estimates of the premium for systematic liquidity risk, though the direction and magnitude of the bias varies depending on specification. However, after correcting for microstructure bias there remains strong evidence of a positive return premium on the Amihud (2002) illiquidity measure as a stock characteristic.

\section{Conclusion and Further Research}

Theory implies that average security returns should be positively related to illiquidity as a security characteristic and/or to measures of systematic illiquidity risk. However, it has been known at least since Blume and Stambaugh (1983) that average observed returns are upward biased, with the magnitude of the bias dependent on the amount of noise in observed prices. This paper has investigated the possibility of upward bias in estimated premia associated with illiquidity. Theory, simulation analysis, and empirical evidence all show that estimated premia for illiquidity obtained by standard cross-sectional methods are indeed significantly upward biased. We also assess via simulations whether a researcher can avoid the biases documented here by excluding securities with wide bid-ask spreads from the analysis. The results indicate that the upward bias in the estimated spread premium can be substantially reduced by excluding wide-spread securities, but at a cost in statistical power such that the researcher may not be able to detect a true illiquidity premium if it exists.

We show that the biases attributable to microstructure noise in prices can be effectively eliminated by a simple methodological correction where return premia are estimated by weighted least squares regressions that rely on individual security returns as the dependent variable, and that use the prior period (one plus) return as the weighting variable. This procedure relies on the same intuition as the Blume and Stambaugh (1983) insight that biases attributable to microstructure noise can be effectively eliminated by the use of "buy-and-hold" returns. In particular, if the prior trade occurred at a price above the efficient price, then the return measured for the current period is decreased on average, while the weight on the current return is increased, and vice versa. This negative covariance between portfolio weights and return measurement errors offsets the original upward return bias attributable to microstructure noise. While the correction relies on the presence of a large sample, simulation evidence indicates substantial bias reduction in a sample with as few as sixty securities, and essentially complete 
elimination of the bias in samples of six hundred or more securities.

The empirical evidence for monthly returns on NYSE/AMEX and Nasdaq stocks provides strong evidence that estimated premia for illiquidity as a stock characteristic are upward biased by microstructure-based measurement errors in prices. This bias exists across subperiods, including the post-decimalization sample. However, after correcting for the upward bias there remains strong evidence of a positive return premium on any of six measures of (il)liquidity as a stock characteristic.

A number of extensions of this analysis may be warranted. While we focus in particular on potential biases in estimates of return premia related to illiquidity, biases due to microstructure noise in prices arise in essentially any empirical application where observed returns are used as the dependent variable. The biases are particularly likely to be important in empirical asset pricing specification where stock level measures are correlated with the amount of microstructure noise in prices. Stock market capitalization and measures of idiosyncratic stock risk, in particular, may well be correlated with microstructure noise. Second, we assumed in our analysis that true security returns are independent of microstructure noise, and that the microstructure noise is independent across securities and across time. It may be of interest to investigate both the magnitude of the biases and the effectiveness of the proposed return-weighting correction in a broader setting where these assumptions are relaxed. Finally, it may be useful to develop models to predict the direction and the magnitude of the microstructure-based bias in estimates of return premia for systematic illiquidity risk. 


\section{Appendix}

\section{A. Proofs of Propositions}

Proof of Proposition 1. Let $D_{n t}=\left(1+\delta_{n t}\right)\left(1-\delta_{n t-1}+\delta_{n t-1}^{2}\right)$. Thus, we can write

$$
R_{n t}^{0} \approx R_{n t} D_{n t}=\left(\alpha+\mathbf{X}_{\mathbf{n t}} \boldsymbol{\beta}+\epsilon_{n t}\right) D_{n t}
$$

Given the definitions of $\boldsymbol{\Gamma}$ and $\boldsymbol{\lambda}$, straight-forward calculations show that the following hold:

1. $\operatorname{Cov}\left(\mathbf{X}_{\mathrm{nt}}, D_{n t} \mathbf{X}_{\mathbf{n t}}-\mathbf{X}_{\mathbf{n t}} \boldsymbol{\Gamma}\right)=\mathbf{0}$

2. $\operatorname{Cov}\left(\mathbf{X}_{\mathbf{n t}}, D_{n t}-\mathbf{X}_{\mathbf{n t}} \boldsymbol{\lambda}\right)=\mathbf{0}$.

Now, write the observed returns as $R_{n t}^{0}=\left(\alpha+\mathbf{X}_{\mathbf{n t}} \boldsymbol{\beta}+\epsilon_{n t}\right) D_{n t}=\alpha \mathbf{X}_{\mathbf{n t}} \boldsymbol{\lambda}+\mathbf{X}_{\mathbf{n t}}(\boldsymbol{\Gamma} \boldsymbol{\beta})+\tilde{\eta}_{n t}$. We have denoted $\tilde{\eta}_{n t}=\alpha\left(-\mathbf{X}_{\mathbf{n t}} \boldsymbol{\lambda}+D_{n t}\right)+\left(-\mathbf{X}_{\mathbf{n t}} \boldsymbol{\Gamma}+D_{n t} \mathbf{X}_{\mathbf{n t}}\right) \boldsymbol{\beta}+\epsilon_{n t} D_{n t}$. Further, denoting $\eta_{n t}=\tilde{\eta}_{n t}-E\left(\tilde{\eta}_{n t}\right)$, we can write

$$
R_{n t}^{0}=E\left(\tilde{\eta}_{n t}\right)+\mathbf{X}_{\mathbf{n t}}(\alpha \boldsymbol{\lambda}+\boldsymbol{\Gamma} \boldsymbol{\beta})+\eta_{n t} .
$$

Using properties 1 and 2 above, it follows that $\operatorname{Cov}\left(\mathbf{X}_{\mathbf{n t}}, \eta_{n t}\right)=\operatorname{Cov}\left(\mathbf{X}_{\mathbf{n t}}, \tilde{\eta}_{n t}\right)=\mathbf{0}$. By construction, $E\left(\eta_{n t}\right)=0$. This implies that the OLS regression of the observed returns $\mathbf{R}_{\mathbf{t}}^{\mathbf{0}}$ on a vector of ones and $\mathbf{X}_{\mathbf{t}}$ produces an intercept coefficient that converges in probability to $E\left(\tilde{\eta}_{n t}\right)$ and a slope coefficients vector that converges in probability to $(\alpha \boldsymbol{\lambda}+\boldsymbol{\Gamma} \boldsymbol{\beta})$. The results for the regression using the same independent variables but the observed net return (i.e., $R_{n t}^{0}-1$ ) as the dependent variable are the same as above for the slope vector. The intercept in the net rate of return regression converges in probability to $E\left(\tilde{\eta}_{n t}\right)-1=\alpha\left(-\boldsymbol{\mu}_{\mathbf{X}} \boldsymbol{\lambda}+\sigma^{2}+1\right)+\left(-\boldsymbol{\mu}_{\mathbf{X}} \boldsymbol{\Gamma}+\left(1+\sigma^{2}\right) \boldsymbol{\mu}_{\mathbf{X}}+\operatorname{Cov}\left(\sigma_{n}^{2}, \mathbf{X}_{\mathbf{n t}}\right)\right) \boldsymbol{\beta}-1$.

Proof of Proposition 2. We first establish the consistency of the WLS estimator and then its normality.

Let $\tilde{\boldsymbol{\beta}}_{\mathbf{O L S}}=\left(\alpha_{O L S}, \boldsymbol{\beta}_{\mathbf{O L S}}^{\prime}\right)^{\prime}=\left[E\left(\tilde{\mathbf{X}}_{\mathbf{n t}}^{\prime} \tilde{\mathbf{X}}_{\mathbf{n t}}\right)\right]^{-1} E\left(\tilde{\mathbf{X}}_{\mathbf{n t}}^{\prime} \tilde{\mathbf{X}}_{\mathbf{n t}}\left(1+\sigma_{n}^{2}\right)\right) \tilde{\boldsymbol{\beta}}$. (The second part of the equation can be established by substituting $\tilde{\boldsymbol{\beta}}$ with $\left(\alpha, \boldsymbol{\beta}^{\prime}\right)^{\prime}$ and $\tilde{\mathbf{X}}_{\mathbf{n t}}^{\prime}$ with $\left(1, \mathbf{X}_{\mathbf{n t}}^{\prime}\right)$.) Then $R_{n t}^{0}=$ 
$\tilde{\mathbf{X}}_{\mathbf{n t}} \tilde{\boldsymbol{\beta}}_{\mathbf{O L S}}+\eta_{n t}$ (see the proof of Proposition 1), with

$$
\eta_{n t}=D_{n t} \tilde{\mathbf{X}}_{\mathbf{n t}} \tilde{\boldsymbol{\beta}}+\epsilon_{n t} D_{n t}-\tilde{\mathbf{X}}_{\mathbf{n t}} \tilde{\boldsymbol{\beta}}_{\mathbf{O L S}}
$$

and $D_{n t}=\left(1+\delta_{n t}\right)\left(1-\delta_{n t-1}+\delta_{n t-1}^{2}\right)=1-\sigma_{n} \delta_{n t-1}^{0}+\sigma_{n}^{2}\left(\delta_{n t-1}^{0}\right)^{2}+\sigma_{n} \delta_{n t}^{0}-\sigma_{n}^{2} \delta_{n t}^{0} \delta_{n t-1}^{0}+\sigma_{n}^{2} \delta_{n t}^{0}\left(\delta_{n t-1}^{0}\right)^{2}$.

Lemma 1. Given the above definitions of $D_{n t}, \eta_{n t}$, and $\tilde{\boldsymbol{\beta}}_{\mathbf{O L S}}$, and if $\mathbf{X}$ denotes all observations of firm characteristics and/or risk measures up to time $t$ then the following hold:

1. $E\left(D_{n t} \mid \mathbf{X}, n\right)=1+\sigma_{n}^{2}$.

2. $E\left(\eta_{n t} \mid \mathbf{X}, n\right)=E\left(D_{n t} \tilde{\mathbf{X}}_{\mathbf{n t}} \tilde{\boldsymbol{\beta}}+\epsilon_{n t} D_{n t}-\tilde{\mathbf{X}}_{\mathbf{n t}} \tilde{\boldsymbol{\beta}}_{\mathbf{O L S}} \mid \mathbf{X}, n\right)=E\left(D_{n t} \mid \mathbf{X}, n\right) \tilde{\mathbf{X}}_{\mathbf{n t}} \tilde{\boldsymbol{\beta}}-\tilde{\mathbf{X}}_{\mathbf{n t}} \tilde{\boldsymbol{\beta}}_{\mathbf{O L S}}=$ $\tilde{\mathbf{X}}_{\mathbf{n t}}\left(\left(1+\sigma_{n}^{2}\right) \tilde{\boldsymbol{\beta}}-\tilde{\boldsymbol{\beta}}_{\mathbf{O L S}}\right)$.

3. $E\left(R_{n t}^{0} \mid \mathbf{X}, n\right)=E\left(X_{n t} \tilde{\boldsymbol{\beta}}_{\mathbf{O L S}}+\eta_{n t} \mid X, n\right)=\tilde{\mathbf{X}}_{\mathbf{n t}} \tilde{\boldsymbol{\beta}}_{\mathbf{O L S}}+E\left(\eta_{n t} \mid X, n\right)=\tilde{\mathbf{X}}_{\mathbf{n t}} \tilde{\boldsymbol{\beta}}_{\mathbf{O L S}}+\tilde{\mathbf{X}}_{\mathbf{n t}}\left(\left(1+\sigma_{n}^{2}\right) \tilde{\boldsymbol{\beta}}_{-}\right.$ $\left.\tilde{\boldsymbol{\beta}}_{\mathbf{O L S}}\right)=\left(1+\sigma_{n}^{2}\right) \tilde{\mathbf{X}}_{\mathbf{n t}} \tilde{\boldsymbol{\beta}}$.

Proof of Lemma 1. Substituting the variables according to their definitions in the above formulas and applying the distributional assumptions about the primitive random variables yields the results.

By the law of large numbers, the convergence in probability of $\boldsymbol{\beta}_{\mathbf{W L S}}$ is expressed as follows

$$
p \lim \boldsymbol{\beta}_{\mathbf{W L S}}=\left(\operatorname{plim} \frac{\tilde{\mathbf{X}}_{\mathbf{t}}^{\prime} \mathbf{W}_{\mathbf{t}} \tilde{\mathbf{X}}_{\mathbf{t}}}{N}\right)^{-1} \operatorname{plim} \frac{\tilde{\mathbf{X}}_{\mathbf{t}}^{\prime} \mathbf{W}_{\mathbf{t}} \mathbf{R}_{\mathbf{t}}^{\mathbf{0}}}{N}=E\left(\tilde{\mathbf{X}}_{\mathbf{n t}}^{\prime} \tilde{\mathbf{X}}_{\mathbf{n t}} R_{n t-1}^{0}\right)^{-1} E\left(\tilde{\mathbf{X}}_{\mathbf{n t}}^{\prime} R_{n t-1}^{0} R_{n t}^{0}\right)
$$

Using Lemma 1, the first factor of Equation (1) is $\operatorname{plim} \frac{\tilde{\mathbf{X}}_{\mathbf{t}}^{\prime} \mathbf{W}_{\mathbf{t}} \tilde{\mathbf{X}}_{\mathbf{t}}}{N}=E\left(\tilde{\mathbf{X}}_{\mathbf{n t}}^{\prime} \tilde{\mathbf{X}}_{\mathbf{n t}} R_{n t-1}^{0}\right)=E\left[E\left(\tilde{\mathbf{X}}_{\mathbf{n t}}^{\prime} \tilde{\mathbf{X}}_{\mathbf{n t}} R_{n t-1}^{0} \mid \mathbf{X}, n\right)\right]=E\left[\tilde{\mathbf{X}}_{\mathbf{n t}}^{\prime} \tilde{\mathbf{X}}_{\mathbf{n t}} E\left(R_{n t-1}^{0} \mid \mathbf{X}, n\right)\right]=$ $E\left[\tilde{\mathbf{X}}_{\mathbf{n t}}^{\prime} \tilde{\mathbf{X}}_{\mathbf{n t}}\left(1+\sigma_{n}^{2}\right)\left(\tilde{\mathbf{X}}_{\mathbf{n t}-\mathbf{1}} \tilde{\boldsymbol{\beta}}\right)\right]$.

The second factor can be written as follows

$$
\begin{aligned}
\operatorname{plim} & \frac{\tilde{\mathbf{X}}_{\mathbf{t}}^{\prime} \mathbf{W}_{\mathbf{t}} \mathbf{R}_{\mathbf{t}}^{\mathbf{0}}}{N}=E\left(\tilde{\mathbf{X}}_{\mathbf{n t}}^{\prime} R_{n t-1}^{0} R_{n t}^{0}\right)=E\left(\tilde{\mathbf{X}}_{\mathbf{n t}}^{\prime}\left(\tilde{\mathbf{X}}_{\mathbf{n t}-\mathbf{1}} \tilde{\boldsymbol{\beta}}_{\mathbf{O L S}}+\eta_{n t-1}\right)\left(\tilde{\mathbf{X}}_{\mathbf{n t}} \tilde{\boldsymbol{\beta}}_{\mathbf{O L S}}+\eta_{n t}\right)\right)= \\
= & \underbrace{E\left(\tilde{\mathbf{X}}_{\mathbf{n t}}^{\prime}\left(\tilde{\mathbf{X}}_{\mathbf{n t}-\mathbf{1}} \tilde{\boldsymbol{\beta}}_{\mathbf{O L S}}\right)\left(\tilde{\mathbf{X}}_{\mathbf{n t}} \tilde{\boldsymbol{\beta}}_{\mathbf{O L S}}\right)\right)}_{T e r m B}+\underbrace{E\left(\tilde{\mathbf{X}}_{\mathbf{n t}}^{\prime}\left(\eta_{n t-1}\right)\left(\eta_{n t}\right)\right)}_{T e r m A}+\underbrace{E\left(\tilde{\mathbf{X}}_{\mathbf{n t}}^{\prime}\left(\eta_{n t-1}\right)\left(\tilde{\mathbf{X}}_{\mathbf{n t}} \tilde{\boldsymbol{\beta}}_{\mathbf{O L S}}\right)\right)}_{T e r m C}+ \\
& +\underbrace{E\left(\tilde{\mathbf{X}}_{\mathbf{n t}}^{\prime}\left(\tilde{\mathbf{X}}_{\mathbf{n t}-\mathbf{1}} \tilde{\boldsymbol{\beta}}_{\mathbf{O L S}}\right)\left(\eta_{n t}\right)\right)}_{\text {Term } D} .
\end{aligned}
$$

Starting with Term D and using Lemma 1, we obtain:

$$
E\left(\tilde{\mathbf{X}}_{\mathbf{n t}}^{\prime}\left(\tilde{\mathbf{X}}_{\mathbf{n t}-\mathbf{1}} \tilde{\boldsymbol{\beta}}_{\mathbf{O L S}}\right)\left(\eta_{n t}\right)\right)=E\left[E\left(\tilde{\mathbf{X}}_{\mathbf{n t}}^{\prime}\left(\tilde{\mathbf{X}}_{\mathbf{n t}-\mathbf{1}} \tilde{\boldsymbol{\beta}}_{\mathbf{O L S}}\right)\left(\eta_{n t}\right) \mid \mathbf{X}, n\right)\right]=E\left[\tilde{\mathbf{X}}_{\mathbf{n t}}^{\prime}\left(\tilde{\mathbf{X}}_{\mathbf{n t}-\mathbf{1}} \tilde{\boldsymbol{\beta}}_{\mathbf{O L S}}\right) E\left(\eta_{n t} \mid \mathbf{X}, n\right)\right]=
$$$$
E\left[\tilde{\mathbf{X}}_{\mathbf{n t}}^{\prime}\left(\tilde{\mathbf{X}}_{\mathbf{n t}-\mathbf{1}} \tilde{\boldsymbol{\beta}}_{\mathbf{O L S}}\right)\left(\tilde{\mathbf{X}}_{\mathbf{n t}}\left(\left(1+\sigma_{n}^{2}\right) \tilde{\boldsymbol{\beta}}-\tilde{\boldsymbol{\beta}}_{\mathbf{O L S}}\right)\right)\right]
$$ 
Similarly, Term C (using Lemma 1) can be written as

$$
\begin{aligned}
& \quad E\left(\tilde{\mathbf{X}}_{\mathbf{n t}}^{\prime}\left(\eta_{n t-1}\right)\left(\tilde{\mathbf{X}}_{\mathbf{n t}} \tilde{\boldsymbol{\beta}}_{\mathbf{O L S}}\right)\right)=E\left[E\left(\tilde{\mathbf{X}}_{\mathbf{n t}}^{\prime}\left(\eta_{n t-1}\right)\left(\tilde{\mathbf{X}}_{\mathbf{n t}} \tilde{\boldsymbol{\beta}}_{\mathbf{O L S}}\right) \mid \mathbf{X}, n\right)\right]=E\left[\tilde{\mathbf{X}}_{\mathbf{n t}}^{\prime}\left(\tilde{\mathbf{X}}_{\mathbf{n t}} \tilde{\boldsymbol{\beta}}_{\mathbf{O L S}}\right) E\left(\eta_{n t-1} \mid \mathbf{X}, n\right)\right]= \\
& E\left[\tilde{\mathbf{X}}_{\mathbf{n t}}^{\prime}\left(\tilde{\mathbf{X}}_{\mathbf{n t}} \tilde{\boldsymbol{\beta}}_{\mathbf{O L S}}\right)\left(\tilde{\mathbf{X}}_{\mathbf{n t}-\mathbf{1}}\left(\left(1+\sigma_{n}^{2}\right) \tilde{\boldsymbol{\beta}}-\tilde{\boldsymbol{\beta}}_{\mathbf{O L S}}\right)\right)\right]
\end{aligned}
$$

The following three Lemmas are used for the computation of Term B.

Lemma 2. If a random variable $A$ has mean of zero and is independent of the random variables $B$ and $C$, then $\operatorname{Cov}(A B, C)=E(A B C)-E(A B) E(C)=E(A) E(B C)-E(A) E(B) E(C)=0$

Lemma 3. Assume that $E\left(\delta_{n t}^{3} \mid n\right)=0$ for all $n$. Then

$\operatorname{Cov}\left(D_{n t-1}, D_{n t} \mid \mathbf{X}, n\right)=-\sigma_{n}^{2}-\sigma_{n}^{4}$

Proof of Lemma 3. $\operatorname{Cov}\left(D_{n t-1}, \quad D_{n t} \mid \mathbf{X}, n\right)=\operatorname{Cov}\left(D_{n t-1}, \quad D_{n t} \mid n\right)=\operatorname{Cov}\left(\left(1+\delta_{n t-1}\right)\left(1-\delta_{n t-2}+\right.\right.$ $\left.\left.\delta_{n t-2}^{2}\right),\left(1+\delta_{n t}\right)\left(1-\delta_{n t-1}+\delta_{n t-1}^{2}\right) \mid n\right)=\operatorname{Cov}\left(1-\delta_{n t-2}+\delta_{n t-2}^{2}+\delta_{n t-1}-\delta_{n t-1} \delta_{n t-2}+\delta_{n t-1} \delta_{n t-2}^{2}, 1-\right.$ $\left.\delta_{n t-1}+\delta_{n t-1}^{2}+\delta_{n t}-\delta_{n t} \delta_{n t-1}+\delta_{n t} \delta_{n t-1}^{2} \mid n\right) \stackrel{\text { Lemma2 }}{=} \operatorname{Cov}\left(\delta_{n t-1}+\delta_{n t-1} \delta_{n t-2}^{2}, \quad-\delta_{n t-1}+\delta_{n t-1}^{2} \mid n\right)=$ $-E\left(\delta_{n t-1}^{2} \mid n\right)-E\left(\delta_{n t-1}^{2} \mid n\right) E\left(\delta_{n t-2}^{2} \mid n\right)=-\sigma_{n}^{2}-\sigma_{n}^{4}$.

Lemma 4. $\operatorname{Cov}\left(\eta_{n t-1}, \eta_{n t} \mid \mathbf{X}, n\right)=\left(-\sigma_{n}^{2}-\sigma_{n}^{4}\right)\left(\tilde{\mathbf{X}}_{\mathbf{n t}-\mathbf{1}} \tilde{\boldsymbol{\beta}}\right)\left(\tilde{\mathbf{X}}_{\mathbf{n t}} \tilde{\boldsymbol{\beta}}\right)$

Proof of Lemma 4. $\operatorname{Cov}\left(\eta_{n t-1}, \eta_{n t} \mid \mathbf{X}, n\right)=\operatorname{Cov}\left(D_{n t-1} \tilde{\mathbf{X}}_{\mathbf{n t}-\mathbf{1}} \tilde{\boldsymbol{\beta}}+\epsilon_{n t-1} D_{n t-1}-\tilde{\mathbf{X}}_{\mathbf{n t}-\mathbf{1}} \tilde{\boldsymbol{\beta}}_{\mathbf{O L S}}, D_{n t} \tilde{\mathbf{X}}_{\mathbf{n t}} \tilde{\boldsymbol{\beta}}_{+}\right.$ $\left.\epsilon_{n t} D_{n t}-\tilde{\mathbf{X}}_{\mathbf{n t}} \tilde{\boldsymbol{\beta}}_{\mathbf{O L S}} \mid \mathbf{X}, n\right)=\operatorname{Cov}\left(D_{n t-1} \tilde{\mathbf{X}}_{\mathbf{n t}-\mathbf{1}} \tilde{\boldsymbol{\beta}}, D_{n t} \tilde{\mathbf{X}}_{\mathbf{n t}} \tilde{\boldsymbol{\beta}} \mid \mathbf{X}, n\right)=\operatorname{Cov}\left(D_{n t-1}, D_{n t} \mid \mathbf{X}, n\right)\left(\tilde{\mathbf{X}}_{\mathbf{n t}-\mathbf{1}} \tilde{\boldsymbol{\beta}}\right)\left(\tilde{\mathbf{X}}_{\mathbf{n t}} \tilde{\boldsymbol{\beta}}\right) \stackrel{L e m m a 3}{=}$ $\left(-\sigma_{n}^{2}-\sigma_{n}^{4}\right)\left(\tilde{\mathbf{X}}_{\mathbf{n t}-\mathbf{1}} \tilde{\boldsymbol{\beta}}\right)\left(\tilde{\mathbf{X}}_{\mathbf{n t}} \tilde{\boldsymbol{\beta}}\right)$.

Using Lemma 4, $E\left(\eta_{n t-1} \eta_{n t} \mid \mathbf{X}, n\right)=\operatorname{Cov}\left(\eta_{n t-1}, \eta_{n t} \mid \mathbf{X}, n\right)+E\left(\eta_{n t-1} \mid \mathbf{X}, n\right) E\left(\eta_{n t} \mid \mathbf{X}, n\right)=\left(-\sigma_{n}^{2}-\right.$ $\left.\sigma_{n}^{4}\right)\left(\tilde{\mathbf{X}}_{\mathbf{n t}-\mathbf{1}} \tilde{\boldsymbol{\beta}}\right)\left(\tilde{\mathbf{X}}_{\mathbf{n t}} \tilde{\boldsymbol{\beta}}\right)+\left(\left(1+\sigma_{n}^{2}\right) \tilde{\mathbf{X}}_{\mathbf{n t}-\mathbf{1}} \tilde{\boldsymbol{\beta}}-\tilde{\mathbf{X}}_{\mathbf{n t}-\mathbf{1}} \tilde{\boldsymbol{\beta}}_{\mathbf{O L S}}\right)\left(\left(1+\sigma_{n}^{2}\right) \tilde{\mathbf{X}}_{\mathbf{n t}} \tilde{\boldsymbol{\beta}}-\tilde{\mathbf{X}}_{\mathbf{n t}} \tilde{\boldsymbol{\beta}}_{\mathbf{O L S}}\right)=\left(-\sigma_{n}^{2}-\right.$ $\left.\sigma_{n}^{4}\right)\left(\tilde{\mathbf{X}}_{\mathbf{n t}-\mathbf{1}} \tilde{\boldsymbol{\beta}}\right)\left(\tilde{\mathbf{X}}_{\mathbf{n t}} \tilde{\boldsymbol{\beta}}\right)+\left(\tilde{\mathbf{X}}_{\mathbf{n t}-\mathbf{1}}\left(\left(1+\sigma_{n}^{2}\right) \tilde{\boldsymbol{\beta}}-\tilde{\boldsymbol{\beta}}_{\mathbf{O L S}}\right)\right)\left(\tilde{\mathbf{X}}_{\mathbf{n t}}\left(\left(1+\sigma_{n}^{2}\right) \tilde{\boldsymbol{\beta}}-\tilde{\boldsymbol{\beta}}_{\mathbf{O L S}}\right)\right)$.

We can write Term B as follows

$E\left(\tilde{\mathbf{X}}_{\mathbf{n t}}^{\prime}\left(\eta_{n t-1}\right)\left(\eta_{n t}\right)\right)=E\left[E\left(\tilde{\mathbf{X}}_{\mathbf{n t}}^{\prime}\left(\eta_{n t-1}\right)\left(\eta_{n t}\right) \mid \mathbf{X}, n\right)\right]=E\left[\tilde{\mathbf{X}}_{\mathbf{n t}}^{\prime} E\left(\eta_{n t-1} \eta_{n t} \mid \mathbf{X}, n\right)\right]=E\left(\left(-\sigma_{n}^{2}-\right.\right.$ $\left.\left.\sigma_{n}^{4}\right) \tilde{\mathbf{X}}_{\mathbf{n t}}^{\prime}\left(\tilde{\mathbf{X}}_{\mathbf{n t}-\mathbf{1}} \tilde{\boldsymbol{\beta}}\right)\left(\tilde{\mathbf{X}}_{\mathbf{n t}} \tilde{\boldsymbol{\beta}}\right)\right)+E\left(\tilde{\mathbf{X}}_{\mathbf{n t}}^{\prime}\left(\tilde{\mathbf{X}}_{\mathbf{n t}-\mathbf{1}}\left(\left(1+\sigma_{n}^{2}\right) \tilde{\boldsymbol{\beta}}-\tilde{\boldsymbol{\beta}}_{\mathbf{O L S}}\right)\right)\left(\tilde{\mathbf{X}}_{\mathbf{n t}}\left(\left(1+\sigma_{n}^{2}\right) \tilde{\boldsymbol{\beta}}_{-} \tilde{\boldsymbol{\beta}}_{\mathbf{O L S}}\right)\right)\right)$.

Summing across the terms we obtain $\operatorname{plim} \frac{\tilde{\mathbf{X}}_{\mathbf{t}}^{\prime} \mathbf{W}_{\mathbf{t}} \mathbf{R}_{\mathbf{t}}^{\mathbf{0}}}{N}=\operatorname{Term} A+\operatorname{Term} B+\operatorname{Term} C+\operatorname{Term} D=E\left(\left(1+\sigma_{n}^{2}\right) \tilde{\mathbf{X}}_{\mathbf{n t}}^{\prime}\left(\tilde{\mathbf{X}}_{\mathbf{n t}-\mathbf{1}} \tilde{\boldsymbol{\beta}}\right)\left(\tilde{\mathbf{X}}_{\mathbf{n t}} \tilde{\boldsymbol{\beta}}\right)\right)$.

Thus,

$$
\begin{gathered}
p l i m \boldsymbol{\beta}_{\mathbf{W L S}}=E\left(\tilde{\mathbf{X}}_{\mathbf{n t}} \tilde{\mathbf{X}}_{\mathbf{n t}}^{\prime} R_{n t-1}^{0}\right)^{-1} E\left(\tilde{\mathbf{X}}_{\mathbf{n t}}^{\prime} R_{n t-1}^{0} R_{n t}^{0}\right)=E\left[\left(1+\sigma_{n}^{2}\right)\left(\tilde{\mathbf{X}}_{\mathbf{n t}-\mathbf{1}} \tilde{\boldsymbol{\beta}}_{)} \tilde{\mathbf{X}}_{\mathbf{n t}}^{\prime} \tilde{\mathbf{X}}_{\mathbf{n t}}\right]^{-1} E((1+\right. \\
\left.\left.\sigma_{n}^{2}\right)\left(\tilde{\mathbf{X}}_{\mathbf{n t}-\mathbf{1}} \tilde{\boldsymbol{\beta}}\right) \tilde{\mathbf{X}}_{\mathbf{n t}}^{\prime}\left(\tilde{\mathbf{X}}_{\mathbf{n t}} \tilde{\boldsymbol{\beta}}\right)\right)=E\left[\left(1+\sigma_{n}^{2}\right)\left(\tilde{\mathbf{X}}_{\mathbf{n t}-\mathbf{1}} \tilde{\boldsymbol{\beta}}\right) \tilde{\mathbf{X}}_{\mathbf{n t}}^{\prime} \tilde{\mathbf{X}}_{\mathbf{n t}}\right]^{-1} E\left(\left(1+\sigma_{n}^{2}\right)\left(\tilde{\mathbf{X}}_{\mathbf{n t}-\mathbf{1}} \tilde{\boldsymbol{\beta}}\right) \tilde{\mathbf{X}}_{\mathbf{n t}}^{\prime} \tilde{\mathbf{X}}_{\mathbf{n t}}\right) \tilde{\boldsymbol{\beta}}=\tilde{\boldsymbol{\beta}}
\end{gathered}
$$


The above establishes the consistency of the WLS estimator. The normality from here is a straightforward application of Amemiya (1996, p. 111), Theorem (4.1.3.) Below we restate the theorem as it applies to our setup.

As before, let $\tilde{\boldsymbol{\beta}}$ denote the true parameter.

Let $\Theta$ be the ( $K$-dimensional) parameter space. We first define

$$
\begin{aligned}
& \mathbf{y}=\left(\left(R_{1 t-1}^{0}, R_{1 t}^{0}, \mathbf{X}_{\mathbf{1 t}}\right),\left(R_{2 t-1}^{0}, R_{2 t}^{0}, \mathbf{X}_{2 \mathbf{t}}\right), \ldots,\left(R_{N t-1}^{0}, R_{N t}^{0}, \mathbf{X}_{\mathbf{N t}}\right)\right) \text { and } \\
& S_{N}(\mathbf{y}, \mathbf{b})=\sum_{n=1}^{N} R_{n t-1}^{0}\left(R_{n t}^{0}-\mathbf{X}_{\mathbf{n t}} \mathbf{b}\right)^{2}=\left(\mathbf{W}_{\mathbf{t}}\left(\mathbf{R}_{\mathbf{t}}^{\mathbf{0}}-\mathbf{X}_{\mathbf{t}} \mathbf{b}\right)\right)^{\prime}\left(\mathbf{R}_{\mathbf{t}}^{\mathbf{0}}-\mathbf{X}_{\mathbf{t}} \mathbf{b}\right) .
\end{aligned}
$$

Theorem 1 (Theorem (4.1.3.), Amemiya.). If

(i) The parameter space $\Theta(\tilde{\boldsymbol{\beta}} \in \Theta)$ is an open subset of the Euclidean $K$-space, $\mathbb{R}^{K}$.

(ii) $S_{N}(\mathbf{y}, \mathbf{b})$ is a measurable function of $\mathbf{y}$ for all $\mathbf{b} \in \Theta$, and $\frac{\partial S_{N}}{\partial \mathbf{b}}$ exists and is continuous in an open neighborhood $N_{1}(\tilde{\boldsymbol{\beta}})$ of $\tilde{\boldsymbol{\beta}}$.

(iii) There exists an open neighborhood $N_{2}(\tilde{\boldsymbol{\beta}})$ of $\tilde{\boldsymbol{\beta}}$ such that $\frac{S_{N}(\mathbf{y}, \mathbf{b})}{N}$ converges to a nonstochastic function $S(\mathbf{b})$ in probability uniformly in $\mathbf{b}$ in $N_{2}(\tilde{\boldsymbol{\beta}})$, and $S(\mathbf{b})$ attains a strict local minimum at $\tilde{\boldsymbol{\beta}}$

(iv) $\frac{\partial^{2} S_{N}}{\partial \mathbf{b} \partial \mathbf{b}^{\prime}}$ exists and is continuous in an open, convex neighborhood of $\tilde{\boldsymbol{\beta}}$

(v) $\left.\frac{\partial^{2} S_{N}}{\partial \mathbf{b} \partial \mathbf{b}^{\prime}}\right|_{\mathbf{b}_{\mathbf{N}}^{*}}$ converges to a finite nonsingular matrix $\mathbf{A}(\tilde{\boldsymbol{\beta}})=\lim E\left(\left.\frac{1}{N} \frac{\partial^{2} S_{N}}{\partial \mathbf{b} \partial \mathbf{b}^{\prime}}\right|_{\mathbf{b}=\tilde{\boldsymbol{\beta}}}\right)$ in probability for any sequence $\mathbf{b}_{\mathbf{N}}^{*}$ such that plim $\mathbf{b}_{\mathbf{N}}^{*}=\tilde{\boldsymbol{\beta}}$.

(vi) $\left.\frac{1}{\sqrt{N}} \frac{\partial S_{N}}{\partial \mathbf{b}}\right|_{\mathbf{b}=\tilde{\boldsymbol{\beta}}} \longrightarrow N[0, \mathbf{B}(\tilde{\boldsymbol{\beta}})]$, where $\mathbf{B}(\tilde{\boldsymbol{\beta}})=\lim E\left(\frac{1}{N}\left(\left.\frac{\partial S_{N}}{\partial \mathbf{b}}\right|_{\mathbf{b}=\tilde{\boldsymbol{\beta}}}\right) \times\left(\left.\frac{\partial S_{N}}{\partial \mathbf{b}^{\prime}}\right|_{\mathbf{b}=\tilde{\boldsymbol{\beta}}}\right)\right)$, and if $\boldsymbol{\beta}_{\mathbf{W L S}}$ is the root of the equation $\frac{\partial S_{N}}{\partial \mathbf{b}}$ then

$$
\frac{1}{\sqrt{N}}\left(\boldsymbol{\beta}_{\mathbf{W L S}}-\tilde{\boldsymbol{\beta}}\right) \longrightarrow N\left[0, A(\tilde{\boldsymbol{\beta}})^{-1} B(\tilde{\boldsymbol{\beta}}) A(\tilde{\boldsymbol{\beta}})^{-1}\right]
$$

Lemma 5. $\boldsymbol{\beta}_{\mathrm{WLS}}=\operatorname{argmin}_{\mathbf{b} \in \Theta} S_{N}(\mathbf{y}, \mathbf{b})$

Proof. $\boldsymbol{\beta}_{\mathbf{W L S}}$ is the only solution of the FOC for the minimization problem $\frac{\partial S_{N}}{\partial \mathbf{b}}=0$.

Below we prove that condition $(i i i)$ holds. The rest of the conditions are trivially satisfied.

Lemma 6. Let $S(\mathbf{b})=\operatorname{plim}\left(\frac{S_{N}(\mathbf{y}, \mathbf{b})}{N}\right)$. Then $\tilde{\boldsymbol{\beta}}=\operatorname{argmin}_{\mathbf{b} \in \Theta} S(\mathbf{b})$.

Proof. The above is equivalent to $\operatorname{plim} \tilde{\boldsymbol{\beta}}_{\mathbf{W L S}}=\tilde{\boldsymbol{\beta}}=E\left(\tilde{\mathbf{X}}_{\mathbf{n t}} \tilde{\mathbf{X}}_{\mathbf{n t}}^{\prime} R_{n t-1}^{0}\right)^{-1} E\left(\tilde{\mathbf{X}}_{\mathbf{n t}}^{\prime} R_{n t-1}^{0} R_{n t}^{0}\right)$, the which is exactly the consistency result of Proposition 2. 


\section{B. The effect of autocorrelation in true security returns}

In what follows we study the properties of the weighted least squares estimator $\boldsymbol{\beta}_{\mathbf{W L S}}$ when the individual returns are autocorrelated.

Proposition 3. When the individual returns are autocorrelated $\boldsymbol{\beta}_{\mathbf{W L S}}=\left(\tilde{\mathbf{X}}_{\mathbf{t}}^{\prime} \mathbf{W}_{\mathbf{t}} \tilde{\mathbf{X}}_{\mathbf{t}}\right)^{-1}\left(\tilde{\mathbf{X}}_{\mathbf{t}}^{\prime} \mathbf{W}_{\mathbf{t}} \mathbf{R}_{\mathbf{t}}^{\mathbf{0}}\right)$ converges in probability to $\tilde{\boldsymbol{\beta}}+E\left[\left(1+\sigma_{n}^{2}\right)\left(R_{n t-1}\right)\left(\tilde{\mathbf{X}}_{\mathbf{n t}}^{\prime} \tilde{\mathbf{X}}_{\mathbf{n t}}\right)\right]^{-1} E\left(\tilde{\mathbf{X}}_{\mathbf{n t}}^{\prime}\left(1+\sigma_{n}^{2}\right) c_{n}\right)$, where $c_{n}=$ $\operatorname{Cov}\left(\epsilon_{n t}, \epsilon_{n t-1} \mid n\right)$.

Proof of Proposition 3. As in the proof of Proposition 2, we write

$$
\operatorname{plim} \boldsymbol{\beta}_{\mathbf{W L S}}=\left(p \lim \frac{\tilde{\mathbf{X}}_{\mathbf{t}}^{\prime} \mathbf{W}_{\mathbf{t}} \tilde{\mathbf{X}}_{\mathbf{t}}}{N}\right)^{-1} p \lim \frac{\tilde{\mathbf{X}}_{\mathbf{t}}^{\prime} \mathbf{W}_{\mathbf{t}} \mathbf{R}_{\mathbf{t}}^{\mathbf{0}}}{N}=E\left(\tilde{\mathbf{X}}_{\mathbf{n t}}^{\prime} \tilde{\mathbf{X}}_{\mathbf{n t}} R_{n t-1}^{0}\right)^{-1} E\left(\tilde{\mathbf{X}}_{\mathbf{n t}}^{\prime} R_{n t-1}^{0} R_{n t}^{0}\right)
$$

The first factor does not depend on the autocorrelation in returns, thus

$\operatorname{plim} \frac{\tilde{\mathbf{X}}_{\mathbf{t}}^{\prime} \mathbf{W}_{\mathbf{t}} \tilde{\mathbf{X}}_{\mathbf{t}}}{N}=E\left[\tilde{\mathbf{X}}_{\mathbf{n t}}^{\prime} \tilde{\mathbf{X}}_{\mathbf{n t}}\left(1+\sigma_{n}^{2}\right)\left(\tilde{\mathbf{X}}_{\mathbf{n t}-\mathbf{1}} \tilde{\boldsymbol{\beta}}\right)\right]$.

As in the proof of Proposition 2, write the second factor as the sum of four terms (see the Proof of Proposition 2)

$\operatorname{plim} \frac{\tilde{\mathbf{X}}_{\mathbf{t}}^{\prime} \mathbf{W}_{\mathbf{t}} \mathbf{R}_{\mathbf{t}}^{\mathbf{0}}}{N}=\operatorname{Term} A+\operatorname{Term} B+\operatorname{Term} C+\operatorname{Term} D$.

Only Term $B$, through its dependence on $E\left(\eta_{n t} \eta_{n t-1} \mid \mathbf{X}, n\right)$ is affected by the returns autocorrelation. Standard computation reveals that $\operatorname{Cov}\left(\eta_{n t-1}, \eta_{n t} \mid \mathbf{X}, n\right)=\left(-\sigma_{n}^{2}-\sigma_{n}^{4}\right)\left(\tilde{\mathbf{X}}_{\mathbf{n t}-\mathbf{1}} \tilde{\boldsymbol{\beta}}\right)\left(\tilde{\mathbf{X}}_{\mathbf{n t}} \tilde{\boldsymbol{\beta}}\right)+c_{n}(1+$ $\left.\sigma_{n}^{2}\right)$, where $c_{n}=\operatorname{Cov}\left(\epsilon_{n t}, \epsilon_{n t-1} \mid n\right)$. From here Term $B$ can be expressed as:

$\operatorname{Term} B=E\left[\tilde{\mathbf{X}}_{\mathbf{n t}}^{\prime} E\left(\eta_{n t-1} \eta_{n t} \mid \mathbf{X}, n\right)\right]=E\left(\tilde{\mathbf{X}}_{\mathbf{n t}}^{\prime}\left(\eta_{n t-1}\right)\left(\eta_{n t}\right)\right)=E\left[E\left(\tilde{\mathbf{X}}_{\mathbf{n t}}^{\prime}\left(\eta_{n t-1}\right)\left(\eta_{n t}\right) \mid \mathbf{X}, n\right)\right]=$ $E\left[\tilde{\mathbf{X}}_{\mathbf{n t}}^{\prime} E\left(\eta_{n t-1} \eta_{n t} \mid \mathbf{X}, n\right)\right]=E\left(\left(-\sigma_{n}^{2}-\sigma_{n}^{4}\right) \tilde{\mathbf{X}}_{\mathbf{n t}}^{\prime}\left(\tilde{\mathbf{X}}_{\mathbf{n t}-\mathbf{1}} \tilde{\boldsymbol{\beta}}\right)\left(\tilde{\mathbf{X}}_{\mathbf{n t}} \tilde{\boldsymbol{\beta}}\right)\right)+E\left(\tilde{\mathbf{X}}_{\mathbf{n t}}^{\prime}\left(\tilde{\mathbf{X}}_{\mathbf{n t}-\mathbf{1}}\left(\left(1+\sigma_{n}^{2}\right) \tilde{\boldsymbol{\beta}}_{-} \tilde{\boldsymbol{\beta}}_{\mathbf{O L S}}\right)\right)\left(\tilde{\mathbf{X}}_{\mathbf{n t}}((1+\right.\right.$ $\left.\left.\left.\left.\sigma_{n}^{2}\right) \tilde{\boldsymbol{\beta}}-\tilde{\boldsymbol{\beta}}_{\mathbf{O L S}}\right)\right)\right)+E\left(\tilde{\mathbf{X}}_{\mathbf{n t}} c_{n}\left(1+\sigma_{n}^{2}\right)\right)$.

Thus, compared to the uncorrelated returns case, Term $B$ changes by $E\left(\tilde{\mathbf{X}}_{\mathbf{n t}} c_{n}\left(1+\sigma_{n}^{2}\right)\right)$.

Lastly, summing up the four terms and multiplying the two factors in the plim expression yields the desired result.

Corollary 4. If $E\left(c_{n}\right)=0$ and $c_{n}$ is independent of $\tilde{\mathbf{X}}_{\mathbf{n t}}$ and $\sigma_{n}^{2}$ then $\boldsymbol{\beta}_{\mathbf{W L S}}$ is a consistent estimate of $\tilde{\boldsymbol{\beta}}$. 
Corollary 5. If $R_{n t-1}, \sigma_{n}^{2}, c_{n}$, and $\tilde{\mathbf{X}}_{\mathbf{n t}}$ are mutually independent for $n=1,2, \cdots, N$ then slope vector is consistently estimated. The bias in the intercept converges in probability to $c / E\left(R_{n t-1}\right)$, where $c=E\left(c_{n}\right)$.

\section{The simulated data}

We create a series of simulated datasets, each containing return data for 43 years (similar to the widely-studied CRSP daily dataset), for 1500 stocks. Simulated true excess return data conforms to the Capital Asset Pricing Model, with a market risk premium of 0.8\% per month, and firm-specific and market standard deviations of $4.5 \%$ and $5.5 \%$, respectively. Beta coefficients are assigned to stocks as random draws from a normal distribution with mean one and standard deviation of 0.4 , which is in line with the estimates reported by Kolb and Rodriguez (1990). With one exception noted in the text, the simulated true return data contains no premium for illiquidity.

Observed return series are constructed from the true return series as follows. An average spread parameter, $s_{i}$, is assigned to each individual stock. For each stock $n$ the actual signed spread on day $t, \delta_{n, t}$, is a random draw from the uniform distribution on the interval $\left[-s_{n}, s_{n}\right]$. The observed return, $r_{n, t}^{o}$, is computed based on the simulated true return and the signed spread as in Eq.(3). The time series of observed and true market returns, which are used to estimate betas, are computed as the simple cross-sectional averages of observed and true security returns.

To obtain reasonable assessments of the potential biases attributable to microstructure noise it is particularly important to select bid-ask spread parameters that are representative of actual spreads in the data typically used to test asset pricing models. We rely on estimates of spreads for NYSE and AMEX stocks as reported by Chalmers and Kadlec (1998) and for Nasdaq stocks as reported by Fortin, Grube, and Joy (1989). In particular, Table 1, Panel B of Chalmers and Kadlec reports average effective spreads (absolute value of trade price less quote midpoint) in percent for ten deciles of NYSE/AMEX securities, estimated over the interval 1983 to 1992. Similarly, Table 1, Panel B of Fortin, Grube, and Joy reports average inside (lowest ask from any dealer minus highest bid from any dealer) spreads for five quintiles of Nasdaq stocks over the period July 1980 to December 1985.

We simulate two research scenarios. The first is that asset pricing tests are conducted using NYSE and AMEX securities, in which case spreads are assigned to individual stocks such that simulated 
mean spreads by decile match the means by deciles as reported by Chalmers and Kadlec (1989). The second scenario focuses on tests conducted using fifty percent Exchange-listed (NYSE and AMEX) stocks and fifty percent Nasdaq stocks. In this case spreads are assigned to individual stocks such that spreads for the first five deciles of the simulated sample correspond to those reported by Chalmers and Kadlec, while spreads for the second half of the sample correspond to mean spreads by quintile as reported by Fortin, Grube, and Joy (1989).

For beta estimation we follow a portfolio grouping method similar to Fama and French (1992). In particular, we form 100 portfolios by first assigning stocks to 10 portfolios based on estimated (by OLS in the first 5 years of observed returns) betas, and then separating each beta portfolio into 10 bid-ask spread portfolios, based on the $s_{i}$ parameter. For purposes of beta estimation portfolio returns are computed on a monthly basis as the equal-weighted average of component stock returns. The estimated portfolio betas are obtained by OLS regressions of portfolio returns on market returns, using the full time series of monthly data. The estimated portfolio beta is then assigned to each stock in the portfolio. Premia for beta risk and spread are estimated as the time series mean of coefficients obtained in cross-sectional monthly regressions of individual security returns on estimated portfolio betas and individual stock spreads. 


\section{References}

Acharya, Viral V. and Lasse Heje Pedersen, 2005, Asset pricing with liquidity risk, Journal of Financial Economics 77, 375-410.

Aït-Sahalia, Yacine, Per A. Mykland and Lan Zhang, 2005, How often to sample a continuous-time process in the presence of market microstructure noise, The Review of Financial Studies 18, 351-416.

Amemiya, Takeshi, 1996, Advanced Econometrics, Harvard University Press, Cambridge, Massachusetts.

Amihud, Yakov, 2002, Illiquidity and stock returns: cross-section and time-series effects, Journal of Financial Markets 5, 31-56.

Amihud, Yakov and Haim Mendelson, 1986, Asset pricing and the bid-ask spread, Journal of Financial Economics 17, 223-249.

Amihud, Yakov, Haim Mendelson and Lasse Heje Pedersen, 2005, Liquidity and asset prices, Foundations and Trends in Finance 1, 269-364.

Andrade, Sandro C., Charles Chang and Mark S. Seasholes, 2008, Trading imbalances, predictable reversals, and cross-stock price pressure, Journal of Financial Economics 88, 406-423.

Ang, Andrew, Jun Liu, and Krista Schwarz, 2009, Using individual stocks or portfolios in tests of factor pricing models, Working Paper.

Bandi, Federico and Jeffrey R. Russell, 2006, Separating microstructure noise from volatility, Journal of Financial Economics, 79, 655-692.

Bessembinder, Hendrik, 2003, Trade execution costs and market quality after decimalization, Journal of Financial and Quantitative Analysis 38, 747-778.

Black, Fisher, 1986, Noise, The Journal of Finance 41, 529-543.

Blume, Marshall E. and Robert F. Stambaugh, 1983, Biases in computed returns: an application to the size effect, Journal of Financial Economics 12, 387-404.

Brennan, Michael J. and Ashley Wang, 2009, The mispricing return premium, Working Paper.

Brennan, Michael J. and A. Subrahmanyam, 1996, Market microstructure and asset pricing: On the compensation for illiquidity in stock returns, Journal of Financial Economics 41, 441-464.

Chalmers, John M. R. and Gregory B. Kadlec, 1998, An empirical examination of the amortized spread, Journal of Financial Economics 48, 159-188.

Chordia, Tarun, Richard Roll and Avanidhar Subrahmanyam, 2000, Commonality in liquidity, Journal of Financial Economics 56, 3-28.

Chordia, Tarun, Richard Roll and Avanidhar Subrahmanyam, 2008, Liquidity and market efficiency, Journal of Financial Economics 87, 249-268.

Constantinides, George M., 1986, Capital market equilibrium with transaction costs, The Journal of Political Economy 94, 842-862.

Dennis, Patrick J. and Stewart Mayhew, 2006, Microstructural biases in empirical tests of option pricing models, Working Paper.

Dorfleitner, Gregor, 2003, Why the return notion matters, International Journal of Theoretical and Applied Finance 6, 73-86. 
Easley, David, Nicholas Kiefer, Maureen O'Hara, and Joseph Paperman, 1996, Liquidity, information, and infrequently traded stocks, The Journal of Finance 51, 1405-1436.

Eleswarapu, Venkat R., 1997, Cost of transacting and expected returns in the NASDAQ market, The Journal of Finance 52, 2113-2127.

Eleswarapu, Venkat R. and Marc R. Reinganum, 1993, The seasonal behavior of the liquidity premium in asset pricing, Journal of Financial Economics 34, 373-386.

Fama, Eugene F. and Kenneth R. French, 1992, The cross-section of expected stock returns, The Journal of Finance 47, 427-465.

Fama, Eugene F. and Kenneth R. French, 1993, Common risk factors in the returns on stocks and bonds, Journal of Financial Economics 33, 3-56.

Fama, Eugene F. and James D. MacBeth, 1973, Risk, return, and equilibrium: empirical tests, The Journal of Political Economy 71, 607-636.

Ferson, Wayne E. and R. A. Korajczyk, 1995, Do arbitrage pricing models explain the predictability of stock returns?, The Journal of Business 68, 309-349.

Fisher, Lawrence, Daniel G. Weaver and Gwendolyn Webb, 2009, Removing biases in computed returns, Review of Quantitative Finance and Accounting, forthcoming.

Fisher, Lawrence and Daniel G. Weaver, 1992, Dealing with short-term anomalies in the relative prices of securities, I: constructing an unbiased equally weighted investment performance index and estimating the standard deviation of the relative "errors", Working Paper, Rutgers University.

Fortin, Richard D., R. Corwin Grube and O. Maurice Joy, 1989, Seasonality in Nasdaq dealer spreads, The Journal of Financial and Quantitative Analysis 24, 395-407.

Fujimoto, Akiko and Masahiro Watanabe, 2008, Time-varying liquidity risk and the cross-section of stock returns, The Review of Financial Studies 21, 2449-2486.

Glosten, Lawrence and Paul Milgrom, 1985, Bid, ask, and transaction prices in a specialist market with heterogeneously informed traders, Journal of Financial Economics 14, 71-100.

Hasbrouck, Joel, 2009, Trading costs and returns for U.S. equities: Estimating effective costs from daily data, The Journal of Finance 64, 1445-1477.

Hasbrouck, Joel and Duane J. Seppi, 2001, Common factors in prices, order flows, and liquidity, Journal of Financial Economics 59, 383-411.

Heaton, John and Deborah J. Lucas, 1996, Evaluating the effects of incomplete markets on risk sharing and asset pricing, The Journal of Political Economy 104, 443-487.

Ho, Thomas and Hans R. Stoll, 1980, On dealer markets under competition, The Journal of Finance $35,259-267$.

Huang, Roger and Hans R. Stoll,1997, The components of the bid-ask spread: A general approach, Review of Financial Studies 10, 995-1034.

Jain, P., 2001, Institutional design and liquidity on stock exchanges, Working Paper.

Jang, Bong-Gyu, Hyeng Keun Koo, Hong Liu and Mark Loewenstein, 2007, Liquidity premia and transaction costs, The Journal of Finance, 62, 2329-2366.

Kolb, Robert W. and Ricardo J. Rodriguez, 1990, Is the distribution of beta stationary? Journal of Financial Research 13, 279-233. 
Korajczyk, Robert and Ronnie Sadka, 2008, Pricing the commonality across alternative measures of liquidity, Journal of Financial Economics 87, 45-72.

Lesmond, David A., Joseph P. Ogden and Charles A. Trzcinka, 1999, A new estimate of transaction costs, The Review of Financial Studies 12, 1113-1141.

Liu, Weimin, 2006, A liquidity-augmented capital asset pricing model, Journal of Financial Economics $82,631-671$.

Merton, Robert C., 1971, Optimum consumption and portfolio rules in a continuous time model, Journal of Economic Theory 3, 373-413.

Pástor, Lubos and Robert F. Stambaugh, 2003, Liquidity risk and expected stock returns, The Journal of Political Economy 111, 642-685.

Peterson, Mitchell A., 2009, Estimating Standard Errors in Finance Panel Data Sets: Comparing Approaches, The Review of Financial Studies 22, 435-480.

Shanken, Jay and Guofu Zhou, 2007, Estimating and testing beta pricing models: alternative methods and their performance in simulations, Journal of Financial Economics, 84, 40-86.

Shanken, Jay, 1992, On the estimation of beta-pricing models, The Review of Financial Studies 5, $1-33$.

Vayanos, Dimitri, 1998, Transaction costs and asset prices: a dynamic equilibrium model, The Review of Financial Studies 11, 1-58 


\section{Table I. Simulation Evidence}

Simulated monthly returns are regressed on estimated betas and spreads, and premia are estimated as the time series mean of the monthly estimates. Panels B and Panel C do not report the estimated market beta premium for brevity. Reported are average estimated premia, average $t$-statistic, and standard errors of mean premia across 250 simulations. Panel A, Column (1) reports results obtained using true returns, while results in Columns (2) and (3) are obtained using observed returns, for a simulated NYSE/AMEX sample and for a simulated NYSE/AMEX/Nasdaq sample, respectively. Panel A, Column (4) replicates the analysis in Column (3), Panel A except that the cross-sectional regressions are estimated by weighted least squares, with the prior period (one plus) return used as the weighting variable. In Panels $\mathrm{A}$ and $\mathrm{C}$ the true beta premium is $0.8 \%$ and the true spread premium is zero. Panel B replicates Panel A, Column (3), except that the spread earns a true premium of $6 \%$. Column (1), Panel B uses all 1500 simulated securities, while each subsequent column reports results after excluding another 10 percent of the sample, beginning with those with the widest average spreads. Panel C assesses results of both OLS and WLS estimation, for differing cross-sectional sample sizes, with a sample of the indicated size drawn at random. Simulation details are in Appendix C.

\section{Panel A: Individual Returns Regressed on Portfolio Betas}

(Beta (premium $=0.8 \%)$ is priced and and spread is not)

\begin{tabular}{ccccc}
\hline & $(1)$ & $(2)$ & $(3)$ & $(4)$ \\
& OLS & OLS & OLS & WLS \\
\hline Return measure & True & Observed & Observed & Observed \\
\hline Mean Beta Premium & 0.798 & 0.796 & 0.792 & 0.787 \\
Mean t-statistic & 3.12 & 3.12 & 3.12 & 3.10 \\
Standard Error of Mean & 0.016 & 0.016 & 0.016 & 0.016 \\
\hline Mean Spread Premium & -0.0008 & 0.0310 & 0.0880 & 0.0001 \\
Mean t-statistic & -0.04 & 7.67 & 25.88 & 0.05 \\
Standard Error of Mean $(\times 100)$ & 0.016 & 0.017 & 0.012 & 0.007 \\
\hline
\end{tabular}

Panel B: Effect of Excluding Wide Spread Securities on OLS estimates of the Spread Premium

$($ Beta $($ premium $=0.8 \%)$ and spread $($ premium $=6 \%)$ are priced)

\begin{tabular}{ccccccccccc}
\hline & $(1)$ & $(2)$ & $(3)$ & $(4)$ & $(5)$ & $(6)$ & $(7)$ & $(8)$ & $(9)$ & $(10)$ \\
Pct of Sample Excluded & $0 \%$ & $10 \%$ & $20 \%$ & $30 \%$ & $40 \%$ & $50 \%$ & $60 \%$ & $70 \%$ & $80 \%$ & $90 \%$ \\
\hline Mean Spread Premium & 0.147 & 0.102 & 0.088 & 0.086 & 0.078 & 0.071 & 0.070 & 0.069 & 0.064 & 0.063 \\
Mean t-statistic & 43.72 & 31.41 & 23.88 & 18.08 & 11.91 & 6.65 & 5.29 & 2.58 & 1.13 & 0.49 \\
Standard Error of Mean $(\times 100)$ & 0.01 & 0.01 & 0.02 & 0.02 & 0.03 & 0.06 & 0.08 & 0.17 & 0.35 & 0.94 \\
\hline
\end{tabular}

Panel C: The Effect of Sample Size on OLS and WLS
Estimates of the Spread Premium

(Beta (premium $=0.8 \%)$ is priced and and spread is not)

\begin{tabular}{cccccccc}
\hline & $(1)$ & $(2)$ & $(13)$ & $(4)$ & $(5)$ & $(6)$ & $(7)$ \\
Number of Stocks in Sample & 60 & 120 & 180 & 240 & 300 & 450 & 600 \\
\hline OLS & & & & & & & \\
Mean Spread Premium & 0.0779 & 0.0833 & 0.0839 & 0.0855 & 0.0868 & 0.0870 & 0.0870 \\
Mean t-statistic & 4.60 & 6.88 & 8.72 & 10.31 & 11.74 & 13.74 & 16.03 \\
Standard Error of Mean $(\times 100)$ & 0.061 & 0.041 & 0.035 & 0.028 & 0.027 & 0.022 & 0.019 \\
\hline WLS & & & & & & & \\
Mean Spread Premium & 0.0056 & 0.0029 & 0.0016 & 0.0012 & 0.0008 & 0.0005 & 0.0002 \\
Mean t-statistic & 0.34 & 0.24 & 0.17 & 0.15 & 0.11 & 0.07 & 0.03 \\
Standard Error of Mean $(\times 100)$ & 0.038 & 0.024 & 0.019 & 0.017 & 0.014 & 0.013 & 0.011 \\
\hline
\end{tabular}


Table II. Summary Statistics.

The table reports mean, median and standard deviation for the six (il)liquidity measures introduced in Section VI A estimated market beta $\left(\beta_{r m}\right)$, the estimated beta on the Hasbrouck (2009) marketwide illiquidity factor $\left(\beta_{z u}\right)$, the estimated beta on the Fama-French SMB factor $\left(\beta_{s m b}\right)$, the estimated beta on the Fama-French HML factor $\left(\beta_{h m l}\right)$, and the logarithm of the stocks' beginning of year market capitalization (Logcap) for the period 1926 - 2006. The mean, median and standard deviation for $\beta_{p s}$ is for the period 1963 - 2005. Illiq, Amivest, and Logvol measures have been standardized as described in the text.

\begin{tabular}{|c|c|c|c|c|c|c|}
\hline \multicolumn{7}{|c|}{ Panel A: Full Sample. } \\
\hline & Mean & Median & St.dev. & Mean & Median & St.dev. \\
\hline & \multicolumn{3}{|c|}{ NYSE/AMEX (1926-2006) } & \multicolumn{3}{|c|}{ Nasdaq (1983-2006) } \\
\hline Illiq & 0.971 & 0.541 & 1.447 & 0.967 & 0.541 & 1.250 \\
\hline Amivest & 1.012 & 0.535 & 2.984 & 1.009 & 0.458 & 2.059 \\
\hline Effective Spread & 0.880 & 0.510 & 1.159 & 1.902 & 1.299 & 1.951 \\
\hline Pctnotrade & 8.145 & 0.354 & 15.697 & 10.932 & 0.793 & 18.317 \\
\hline Pctzero & 19.922 & 18.181 & 11.764 & 20.616 & 20.948 & 13.139 \\
\hline Logvol & -1.059 & -0.948 & 1.623 & -1.479 & -1.348 & 1.807 \\
\hline$\beta_{r m}$ & 1.034 & 1.028 & 0.268 & 1.012 & 1.016 & 0.245 \\
\hline$\beta_{z u}$ & 0.320 & 0.268 & 1.469 & 0.326 & 0.348 & 1.282 \\
\hline$\beta_{p s}$ & 0.886 & 3.101 & 4.348 & -1.565 & -1.295 & 3.414 \\
\hline$\beta_{s m b}$ & 0.707 & 0.570 & 0.558 & 0.985 & 0.880 & 0.332 \\
\hline$\beta_{h m l}$ & 0.454 & 0.394 & 0.256 & 0.111 & 0.265 & 0.373 \\
\hline Logcap & 11.308 & 11.120 & 2.254 & 11.086 & 10.996 & 1.640 \\
\hline
\end{tabular}

Panel B: Subperiods.

\begin{tabular}{|c|c|c|c|c|c|c|c|c|c|}
\hline & Mean & Median & St.dev. & Mean & Median & St.dev. & Mean & Median & St.dev. \\
\hline$\overline{N Y S E / A M E X}$ & \multicolumn{3}{|c|}{$(1927-1962)$} & \multicolumn{3}{|c|}{$(1963-2000)$} & \multicolumn{3}{|c|}{$(2001-2006)$} \\
\hline Illiq & 0.984 & 0.705 & 1.076 & 0.971 & 0.507 & 1.436 & 0.941 & 0.179 & 2.197 \\
\hline Amivest & 1.005 & 0.617 & 2.030 & 1.014 & 0.492 & 3.442 & 1.018 & 0.531 & 1.404 \\
\hline Effective Spread & 1.022 & 0.606 & 1.439 & 0.865 & 0.504 & 1.057 & 0.600 & 0.340 & 0.890 \\
\hline Pctnotrade & 16.456 & 6.040 & 21.241 & 5.523 & 0 & 12.082 & 3.465 & 0 & 10.867 \\
\hline Pctzero & 20.825 & 18.918 & 10.080 & 21.549 & 19.521 & 11.540 & 6.558 & 2.777 & 8.580 \\
\hline Logvol & -0.800 & -0.748 & 1.332 & -1.065 & -0.987 & 1.603 & -1.721 & -1.467 & 2.181 \\
\hline$\beta_{r m}$ & 1.032 & 1.028 & 0.268 & 1.034 & 1.028 & 0.268 & 1.036 & 1.006 & 0.265 \\
\hline$\beta_{z u}$ & 0.321 & 0.268 & 1.488 & 0.315 & 0.268 & 1.462 & 0.344 & 0.268 & 1.459 \\
\hline$\beta_{p s}$ & - & - & - & 0.900 & 3.101 & 4.349 & 0.771 & 2.679 & 4.322 \\
\hline$\beta_{s m b}$ & 0.708 & 0.570 & 0.560 & 0.707 & 0.570 & 0.558 & 0.710 & 0.570 & 0.557 \\
\hline$\beta_{h m l}$ & 0.455 & 0.394 & 0.256 & 0.454 & 0.394 & 0.255 & 0.451 & 0.394 & 0.258 \\
\hline Logcap & 9.961 & 9.906 & 1.767 & 11.551 & 11.439 & 2.114 & 13.293 & 13.530 & 2.290 \\
\hline Nasdaq & & & & \multicolumn{3}{|c|}{$(1983-2000)$} & \multicolumn{3}{|c|}{$(2001-2006)$} \\
\hline Illiq & - & - & - & 0.973 & 0.575 & 1.222 & 0.953 & 0.448 & 1.320 \\
\hline Amivest & - & - & - & 1.003 & 0.481 & 1.779 & 1.024 & 0.403 & 2.643 \\
\hline Effective Spread & - & - & - & 2.217 & 1.627 & 2.120 & 1.097 & 0.750 & 1.066 \\
\hline Pctnotrade & - & - & - & 12.788 & 1.984 & 19.522 & 6.188 & 0 & 13.699 \\
\hline Pctzero & - & - & - & 25.674 & 25.000 & 11.216 & 7.683 & 5.158 & 7.727 \\
\hline Logvol & - & - & - & -1.210 & -1.155 & 1.589 & -2.167 & -2.043 & 2.122 \\
\hline$\beta_{r m}$ & - & - & - & 1.010 & 1.016 & 0.244 & 1.016 & 1.016 & 0.245 \\
\hline$\beta_{z u}$ & - & - & - & 0.328 & 0.348 & 1.305 & 0.321 & 0.348 & 1.220 \\
\hline$\beta_{p s}$ & - & - & - & -1.501 & -1.295 & 3.427 & -1.759 & -1.915 & 3.366 \\
\hline$\beta_{s m b}$ & - & - & - & 0.984 & 0.880 & 0.332 & 0.988 & 0.880 & 0.331 \\
\hline$\beta_{h m l}$ & - & - & - & 0.113 & 0.265 & 0.371 & 0.106 & 0.265 & 0.379 \\
\hline Logcap & - & - & - & 10.835 & 10.751 & 1.531 & 11.729 & 11.694 & 1.729 \\
\hline
\end{tabular}


Table III. Empirical Evidence for NYSE/AMEX stocks, 1926 - 2006, for Alternate (Il)liquidity Measures.

Reported are results of implementing cross-sectional Fama-MacBeth regressions using monthly return data for NYSEAMEX stocks over the 1926 to 2006 interval. Panel A reports results where monthly returns are regressed on the estimated market beta and individual illiquidity measures in turn. Panel B reports results for a regression specification where all illiquidity measures are included. The coefficients reported in Column OLS are the time-series means of the monthly cross-sectional OLS regression estimates, while coefficients reported in Column WLS are the time-series means of the monthly cross-sectional WLS regression estimates, where the weighting variable is one plus previous month return. The coefficients reported in Column DIF are the time-series means of the difference between the OLS and WLS coefficient. T-statistics are reported in parenthesis and incorporate the Shanken (1992) correction.

\begin{tabular}{|c|c|c|c|}
\hline & $\begin{array}{c}\text { OLS } \\
\text { Mean }(t \text {-statistic })\end{array}$ & $\begin{array}{c}\text { WLS } \\
\text { Mean }(t \text {-statistic })\end{array}$ & $\begin{array}{c}\text { DIF } \\
\text { Mean }(t \text {-statistic })\end{array}$ \\
\hline \multicolumn{4}{|c|}{ Panel A: Results for each illiquidity variable. } \\
\hline Illiq & 0.356 & 0.230 & 0.125 \\
\hline$(t-s t a t)$ & $(5.04)$ & $(3.47)$ & $(9.40)$ \\
\hline Betarm & 0.163 & 0.088 & 0.075 \\
\hline (t-stat) & $(0.66)$ & $(0.35)$ & $(3.74)$ \\
\hline Amivest & -0.094 & -0.065 & -0.028 \\
\hline$(t-s t a t)$ & $(-3.31)$ & $(-2.36)$ & $(-10.39)$ \\
\hline Betarm & -0.020 & -0.053 & 0.033 \\
\hline (t-stat) & $(-0.08)$ & $(-0.22)$ & $(2.22)$ \\
\hline Effective Spread & 0.329 & 0.184 & 0.144 \\
\hline$(t$-stat) & $(4.17)$ & $(2.41)$ & (15.93) \\
\hline Betarm & -0.003 & -0.025 & 0.021 \\
\hline (t-stat) & $(-0.01)$ & $(-0.10)$ & $(1.35)$ \\
\hline Pctnotrade & 0.017 & 0.013 & 0.004 \\
\hline$(t$-stat) & $(5.91)$ & $(4.65)$ & $(10.50)$ \\
\hline Betarm & 0.407 & 0.274 & 0.132 \\
\hline (t-stat) & $(1.48)$ & $(1.02)$ & $(6.41)$ \\
\hline Pctzero & 0.032 & 0.021 & 0.010 \\
\hline (t-stat) & $(4.43)$ & $(3.08)$ & $(12.39)$ \\
\hline Betarm & 0.364 & 0.221 & 0.143 \\
\hline (t-stat) & $(1.31)$ & $(0.81)$ & $(6.93)$ \\
\hline Logvol & -0.206 & -0.157 & -0.048 \\
\hline$(t-s t a t)$ & $(-5.47)$ & $(-4.42)$ & $(-11.89)$ \\
\hline Betarm & 0.550 & 0.390 & 0.160 \\
\hline$(t$-stat) & $(1.91)$ & $(1.39)$ & $(7.38)$ \\
\hline \multicolumn{4}{|c|}{ Panel B: Results when All Illiquidity Measures are Included Simultaneously } \\
\hline Illiq & 0.244 & 0.172 & 0.072 \\
\hline$(t-s t a t)$ & $(3.41)$ & $(2.42)$ & $(4.76)$ \\
\hline Amivest & -0.014 & -0.011 & -0.002 \\
\hline (t-stat) & $(-0.46)$ & $(-0.37)$ & $(-1.11)$ \\
\hline Effective Spread & 0.016 & -0.061 & 0.078 \\
\hline$(t$-stat) & $(0.22)$ & $(-0.84)$ & $(6.10)$ \\
\hline Pctnotrade & -0.005 & -0.003 & -0.001 \\
\hline$(t$-stat) & $(-1.92)$ & $(-1.27)$ & $(-3.77)$ \\
\hline Pctzero & 0.004 & 0.005 & -0.001 \\
\hline (t-stat) & $(0.84)$ & $(1.05)$ & $(-1.46)$ \\
\hline Logvol & -0.034 & -0.040 & 0.006 \\
\hline (t-stat) & $(-0.75)$ & $(-0.89)$ & $(1.28)$ \\
\hline
\end{tabular}




\section{Table IV. Sensitivity of Results for NYSE/AMEX Stocks to the Inclusion of Additional Explanatory Variables.}

Reported are results of implementing cross-sectional Fama-MacBeth regressions of monthly stock returns on NYSEAMEX stocks from 1926 to 2006 on the estimated market beta $\left(\beta_{r m}\right)$ and the Amihud (2002) illiquidity measure (Illiq). Additional explanatory variables include the estimated beta on the Hasbrouck (2009) marketwide illiquidity factor $\left(\beta_{z u}\right)$, the estimated beta on the Fama-French SMB factor $\left(\beta_{s m b}\right)$, the estimated beta on the Fama-French HML factor $\left(\beta_{h m l}\right)$, and the logarithm of the stocks' beginning of year market capitalization (Logcap). Columns headed OLS, WLS and DIF are as explained in Table III.

\begin{tabular}{|c|c|c|c|c|c|c|c|c|c|}
\hline & $\begin{array}{c}\text { OLS } \\
\text { (Mean } \\
t \text {-stat.) }\end{array}$ & $\begin{array}{c}\text { WLS } \\
\text { (Mean } \\
t \text {-stat.) }\end{array}$ & $\begin{array}{c}\text { DIF } \\
\text { (Mean } \\
t \text {-stat.) }\end{array}$ & $\begin{array}{c}\text { OLS } \\
\text { (Mean } \\
t \text {-stat.) }\end{array}$ & $\begin{array}{c}\text { WLS } \\
\text { (Mean } \\
t \text {-stat.) }\end{array}$ & $\begin{array}{c}\text { DIF } \\
\text { (Mean } \\
\text { t-stat.) }\end{array}$ & $\begin{array}{c}\text { OLS } \\
\text { (Mean } \\
t \text {-stat.) }\end{array}$ & $\begin{array}{c}\text { WLS } \\
\text { (Mean } \\
t \text {-stat.) }\end{array}$ & $\begin{array}{c}\text { DIF } \\
\text { (Mean } \\
t \text {-stat.) }\end{array}$ \\
\hline & \multicolumn{3}{|c|}{ (1) } & \multicolumn{3}{|c|}{ (2) } & \multicolumn{3}{|c|}{ (3) } \\
\hline Illiq & $\begin{array}{l}0.356 \\
(5.04)\end{array}$ & $\begin{array}{l}0.230 \\
(3.47)\end{array}$ & $\begin{array}{l}0.125 \\
(9.40)\end{array}$ & $\begin{array}{l}0.344 \\
(5.58)\end{array}$ & $\begin{array}{l}0.232 \\
(3.92)\end{array}$ & $\begin{array}{l}0.112 \\
(8.56)\end{array}$ & $\begin{array}{l}0.316 \\
(5.25)\end{array}$ & $\begin{array}{l}0.210 \\
(3.58)\end{array}$ & $\begin{array}{c}0.105 \\
(10.37)\end{array}$ \\
\hline$\beta_{r m}$ & $\begin{array}{l}0.163 \\
(0.66)\end{array}$ & $\begin{array}{l}0.088 \\
(0.35)\end{array}$ & $\begin{array}{l}0.075 \\
(3.74)\end{array}$ & $\begin{array}{l}0.124 \\
(0.52)\end{array}$ & $\begin{array}{l}0.131 \\
(0.53)\end{array}$ & $\begin{array}{l}-0.006 \\
(-0.21)\end{array}$ & $\begin{array}{l}0.029 \\
(0.12)\end{array}$ & $\begin{array}{l}-0.011 \\
(-0.04)\end{array}$ & $\begin{array}{l}0.040 \\
(1.90)\end{array}$ \\
\hline$\beta_{z u}$ & $\begin{array}{l}- \\
-\end{array}$ & $\begin{array}{l}- \\
-\end{array}$ & $\begin{array}{l}- \\
-\end{array}$ & $\begin{array}{l}0.010 \\
(0.24)\end{array}$ & $\begin{array}{l}-0.011 \\
(-0.26)\end{array}$ & $\begin{array}{l}0.021 \\
(2.80)\end{array}$ & $\begin{array}{l}- \\
-\end{array}$ & $\begin{array}{l}- \\
-\end{array}$ & $\begin{array}{l}- \\
-\end{array}$ \\
\hline$\beta_{s m b}$ & $\begin{array}{l}- \\
-\end{array}$ & $\begin{array}{l}- \\
-\end{array}$ & $\begin{array}{l}- \\
-\end{array}$ & $\begin{array}{l}- \\
-\end{array}$ & $\begin{array}{l}- \\
-\end{array}$ & $\begin{array}{l}- \\
-\end{array}$ & $\begin{array}{l}-0.170 \\
(-1.00)\end{array}$ & $\begin{array}{l}-0.185 \\
(-1.06)\end{array}$ & $\begin{array}{l}0.015 \\
(0.52)\end{array}$ \\
\hline$\beta_{h m l}$ & - & - & - & - & - & $\begin{array}{l}- \\
- \\
-\end{array}$ & $\begin{array}{l}0.591 \\
(1.90)\end{array}$ & $\begin{array}{l}0.540 \\
(1.71)\end{array}$ & $\begin{array}{l}0.050 \\
(0.82)\end{array}$ \\
\hline Logcap & - & $\begin{array}{l}- \\
-\end{array}$ & $\begin{array}{l}- \\
-\end{array}$ & - & - & - & $\begin{array}{l}- \\
-\end{array}$ & $\begin{array}{l}- \\
-\end{array}$ & $\begin{array}{l}- \\
-\end{array}$ \\
\hline & \multicolumn{3}{|c|}{ (4) } & \multicolumn{3}{|c|}{ (5) } & \multicolumn{3}{|c|}{ (6) } \\
\hline Illiq & $\begin{array}{l}0.315 \\
(5.15)\end{array}$ & $\begin{array}{l}0.209 \\
(3.39)\end{array}$ & $\begin{array}{c}0.105 \\
(10.49)\end{array}$ & $\begin{array}{l}0.324 \\
(5.59)\end{array}$ & $\begin{array}{l}0.224 \\
(3.92)\end{array}$ & $\begin{array}{c}0.100 \\
(10.07)\end{array}$ & $\begin{array}{l}0.324 \\
(5.59)\end{array}$ & $\begin{array}{l}0.225 \\
(3.83)\end{array}$ & $\begin{array}{c}0.099 \\
(10.03)\end{array}$ \\
\hline$\beta_{r m}$ & $\begin{array}{l}0.091 \\
(0.36)\end{array}$ & $\begin{array}{l}0.126 \\
(0.48)\end{array}$ & $\begin{array}{l}-0.034 \\
(-1.42)\end{array}$ & $\begin{array}{l}0.006 \\
(0.02)\end{array}$ & $\begin{array}{l}-0.034 \\
(-0.13)\end{array}$ & $\begin{array}{l}0.040 \\
(1.83)\end{array}$ & $\begin{array}{l}0.037 \\
(0.16)\end{array}$ & $\begin{array}{l}0.083 \\
(0.33)\end{array}$ & $\begin{array}{l}-0.045 \\
(-1.78)\end{array}$ \\
\hline$\beta_{z u}$ & $\begin{array}{l}-0.031 \\
(-0.91)\end{array}$ & $\begin{array}{l}-0.062 \\
(-1.74)\end{array}$ & $\begin{array}{l}0.031 \\
(4.13)\end{array}$ & $\begin{array}{l}- \\
-\end{array}$ & $\begin{array}{l}- \\
-\end{array}$ & $\begin{array}{l}- \\
-\end{array}$ & $\begin{array}{l}-0.017 \\
(-0.50)\end{array}$ & $\begin{array}{l}-0.053 \\
(-1.48)\end{array}$ & $\begin{array}{l}0.036 \\
(4.44)\end{array}$ \\
\hline$\beta_{s m b}$ & $\begin{array}{l}-0.161 \\
(-0.95)\end{array}$ & $\begin{array}{l}-0.157 \\
(-0.88)\end{array}$ & $\begin{array}{l}-0.004 \\
(-0.15)\end{array}$ & $\begin{array}{l}-0.208 \\
(-1.49)\end{array}$ & $\begin{array}{l}-0.195 \\
(-1.36)\end{array}$ & $\begin{array}{l}-0.012 \\
(-0.44)\end{array}$ & $\begin{array}{l}-0.197 \\
(-1.41)\end{array}$ & $\begin{array}{l}-0.156 \\
(-1.07)\end{array}$ & $\begin{array}{l}-0.040 \\
(-1.40)\end{array}$ \\
\hline$\beta_{h m l}$ & $\begin{array}{l}0.705 \\
(2.18)\end{array}$ & $\begin{array}{l}0.733 \\
(2.16)\end{array}$ & $\begin{array}{l}-0.028 \\
(-0.45)\end{array}$ & $\begin{array}{l}0.603 \\
(1.97)\end{array}$ & $\begin{array}{l}0.531 \\
(1.71)\end{array}$ & $\begin{array}{l}0.072 \\
(1.16)\end{array}$ & $\begin{array}{l}0.664 \\
(2.10)\end{array}$ & $\begin{array}{l}0.682 \\
(2.07)\end{array}$ & $\begin{array}{l}-0.018 \\
(-0.30)\end{array}$ \\
\hline Logcap & $\begin{array}{l}- \\
-\end{array}$ & $\begin{array}{l}- \\
-\end{array}$ & $\begin{array}{l}- \\
- \\
\end{array}$ & $\begin{array}{l}-0.004 \\
(-0.15)\end{array}$ & $\begin{array}{l}0.003 \\
(0.12)\end{array}$ & $\begin{array}{l}-0.008 \\
(-2.45)\end{array}$ & $\begin{array}{l}-0.001 \\
(-0.06)\end{array}$ & $\begin{array}{l}0.008 \\
(0.29)\end{array}$ & $\begin{array}{l}-0.010 \\
(-2.99)\end{array}$ \\
\hline
\end{tabular}




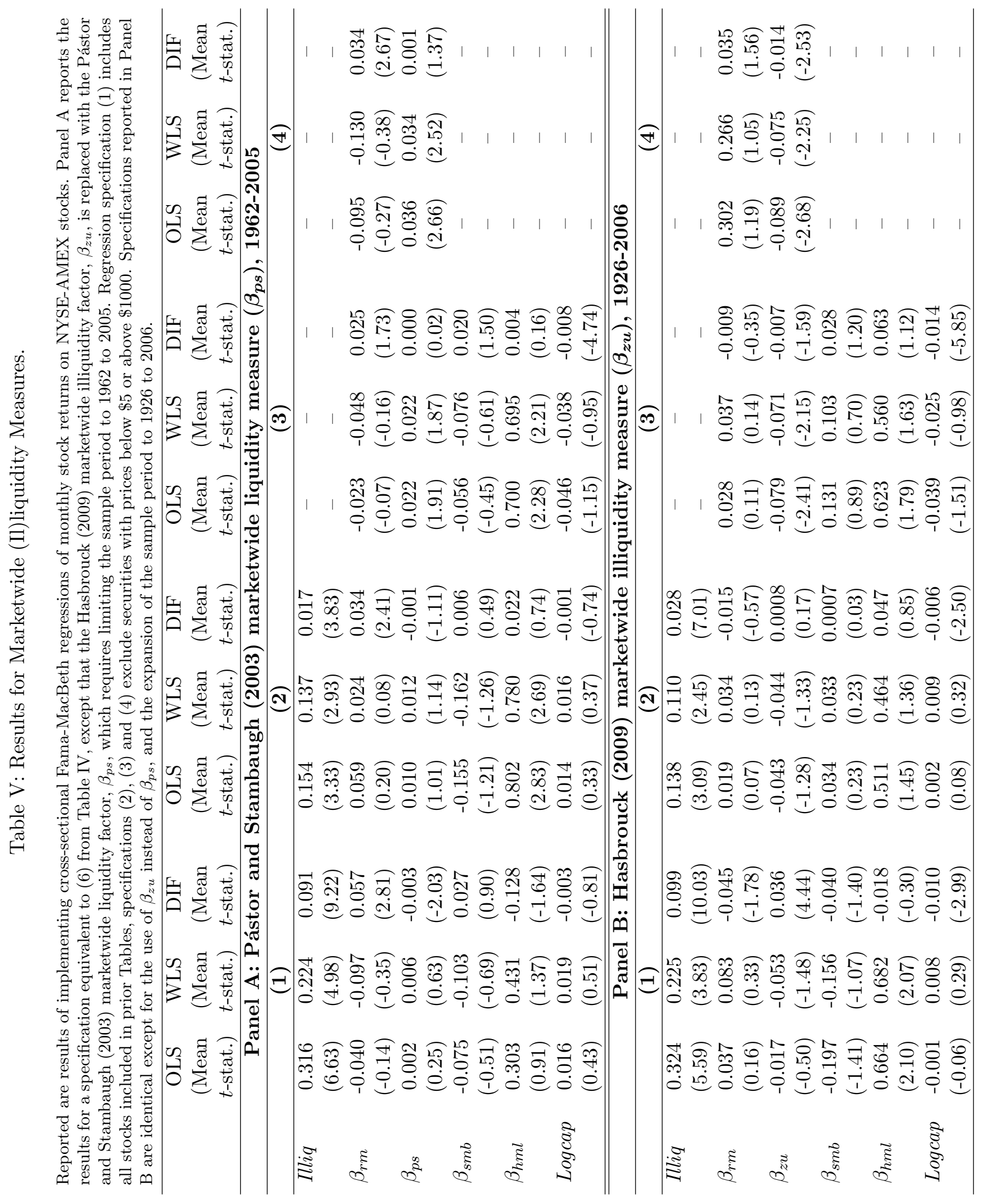


Table VI. Subperiod Results for NYSE/AMEX Stocks

Reported are results of implementing cross-sectional Fama-MacBeth regressions of monthly stock returns on NYSEAMEX stocks from 1926 to 2006 on the estimated market beta $\left(\beta_{r m}\right)$ and the Amihud (2002) illiquidity measure (Illiq). Additional explanatory variables include the estimated beta on the Hasbrouck (2009) marketwide illiquidity factor $\left(\beta_{z u}\right)$, the estimated beta on the Fama-French SMB factor $\left(\beta_{s m b}\right)$, the estimated beta on the Fama-French HML factor $\left(\beta_{h m l}\right)$, and the logarithm of the stocks' beginning of year market capitalization (Logcap). Columns headed OLS, WLS and DIF are as explained in Table III.

\begin{tabular}{|c|c|c|c|c|c|c|}
\hline & $\begin{array}{c}\text { OLS } \\
\text { (Mean } \\
t \text {-stat.) }\end{array}$ & $\begin{array}{c}\text { WLS } \\
\text { (Mean } \\
\text { t-stat.) }\end{array}$ & $\begin{array}{c}\text { DIF } \\
\text { (Mean } \\
t \text {-stat.) }\end{array}$ & $\begin{array}{c}\text { OLS } \\
\text { (Mean } \\
\text { t-stat.) }\end{array}$ & $\begin{array}{c}\text { WLS } \\
\text { (Mean } \\
t \text {-stat.) }\end{array}$ & $\begin{array}{c}\text { DIF } \\
\text { (Mean } \\
t \text {-stat.) }\end{array}$ \\
\hline \multicolumn{7}{|c|}{ Panel A: 1927 - 1962} \\
\hline \multirow[t]{2}{*}{ Illiq } & 0.398 & 0.241 & 0.157 & 0.336 & 0.225 & 0.111 \\
\hline & $(3.07)$ & $(2.00)$ & $(5.69)$ & $(2.85)$ & $(1.84)$ & $(6.05)$ \\
\hline \multirow[t]{2}{*}{$\beta_{r m}$} & 0.354 & 0.325 & 0.029 & 0.334 & 0.422 & -0.087 \\
\hline & $(0.77)$ & $(0.71)$ & $(0.83)$ & $(0.78)$ & $(0.93)$ & $(-1.85)$ \\
\hline \multirow[t]{2}{*}{$\beta_{z u}$} & - & - & - & -0.063 & -0.091 & 0.027 \\
\hline & - & - & - & $(-1.02)$ & $(-1.39)$ & $(2.14)$ \\
\hline \multirow[t]{2}{*}{$\beta_{s m b}$} & - & - & - & 0.010 & 0.032 & -0.022 \\
\hline & - & - & - & $(0.04)$ & $(0.13)$ & $(-0.43)$ \\
\hline \multirow[t]{2}{*}{$\beta_{h m l}$} & - & - & - & 0.615 & 0.624 & -0.009 \\
\hline & - & - & - & $(1.11)$ & $(1.08)$ & $(-0.09)$ \\
\hline \multirow[t]{2}{*}{ Logcap } & - & - & - & -0.006 & 0.009 & -0.016 \\
\hline & - & - & - & $(-0.14)$ & $(0.20)$ & $(-2.53)$ \\
\hline \multicolumn{7}{|c|}{ Panel B: 1963 - 2000} \\
\hline \multirow[t]{2}{*}{ Illiq } & 0.322 & 0.218 & 0.104 & 0.333 & 0.238 & 0.094 \\
\hline & $(3.90)$ & $(2.75)$ & $(10.91)$ & $(6.11)$ & $(4.69)$ & $(8.49)$ \\
\hline \multirow[t]{2}{*}{$\beta_{r m}$} & -0.011 & -0.110 & 0.099 & -0.283 & -0.273 & -0.009 \\
\hline & $(-0.04)$ & $(-0.43)$ & $(4.50)$ & $(-1.08)$ & $(-1.04)$ & $(-0.37)$ \\
\hline \multirow[t]{2}{*}{$\beta_{z u}$} & - & - & - & 0.015 & -0.022 & 0.037 \\
\hline & - & - & - & $(0.35)$ & $(-0.52)$ & $(3.53)$ \\
\hline \multirow[t]{2}{*}{$\beta_{s m b}$} & - & - & - & -0.332 & -0.280 & -0.051 \\
\hline & - & - & - & $(-1.99)$ & $(-1.61)$ & $(-1.67)$ \\
\hline \multirow[t]{2}{*}{$\beta_{h m l}$} & - & - & - & 0.669 & 0.675 & -0.005 \\
\hline & - & - & - & $(1.81)$ & $(1.73)$ & $(-0.07)$ \\
\hline \multirow[t]{2}{*}{ Logcap } & - & - & - & 0.033 & 0.040 & -0.006 \\
\hline & - & - & - & $(0.77)$ & $(0.94)$ & $(-1.63)$ \\
\hline \multicolumn{7}{|c|}{ Panel C: 2001 - 2006} \\
\hline \multirow[t]{2}{*}{ Illiq } & 0.313 & 0.246 & 0.067 & 0.196 & 0.134 & 0.061 \\
\hline & $(2.95)$ & $(2.60)$ & $(3.25)$ & $(2.51)$ & $(1.78)$ & $(3.15)$ \\
\hline \multirow[t]{2}{*}{$\beta_{r m}$} & 0.131 & -0.070 & 0.201 & 0.294 & 0.311 & -0.016 \\
\hline & $(0.15)$ & $(-0.08)$ & $(2.31)$ & $(0.28)$ & $(0.31)$ & $(-0.19)$ \\
\hline \multirow[t]{2}{*}{$\beta_{z u}$} & - & - & - & 0.051 & -0.025 & 0.076 \\
\hline & - & - & - & $(0.38)$ & $(-0.20)$ & $(2.29)$ \\
\hline \multirow[t]{2}{*}{$\beta_{s m b}$} & - & - & - & -0.587 & -0.512 & -0.075 \\
\hline & - & - & - & $(-0.81)$ & $(-0.74)$ & $(-0.67)$ \\
\hline \multirow[t]{2}{*}{$\beta_{h m l}$} & - & - & - & 0.922 & 1.077 & -0.154 \\
\hline & - & - & - & $(0.60)$ & $(0.74)$ & $(-0.60)$ \\
\hline \multirow[t]{2}{*}{ Logcap } & - & - & - & -0.196 & -0.192 & -0.004 \\
\hline & - & - & - & $(-1.71)$ & $(-1.81)$ & $(-0.35)$ \\
\hline
\end{tabular}


Table VII. Estimated Return Premia for Nasdaq Stocks, 1983 - 2006.

Reported are results of implementing cross-sectional Fama-MacBeth regressions of monthly stock returns on Nasdaq stocks from 1983 to 2006 on the estimated market beta $\left(\beta_{r m}\right)$ and the Amihud (2002) illiquidity measure (Illiq). Additional explanatory variables include the estimated beta on the Hasbrouck (2009) marketwide illiquidity factor $\left(\beta_{z u}\right)$, the estimated beta on the Fama-French SMB factor $\left(\beta_{s m b}\right)$, the estimated beta on the Fama-French HML factor $\left(\beta_{h m l}\right)$, and the logarithm of the stocks' beginning of year market capitalization (Logcap). Columns headed OLS, WLS and DIF are as explained in Table III

\begin{tabular}{|c|c|c|c|c|c|c|}
\hline & $\begin{array}{c}\text { OLS } \\
\text { (Mean } \\
t \text {-stat.) }\end{array}$ & $\begin{array}{c}\text { WLS } \\
\text { (Mean } \\
t \text {-stat.) }\end{array}$ & $\begin{array}{c}\text { DIF } \\
\text { (Mean } \\
t \text {-stat.) }\end{array}$ & $\begin{array}{c}\text { OLS } \\
\text { (Mean } \\
t \text {-stat.) }\end{array}$ & $\begin{array}{c}\text { WLS } \\
\text { (Mean } \\
t \text {-stat.) }\end{array}$ & $\begin{array}{c}\text { DIF } \\
\text { (Mean } \\
t \text {-stat.) }\end{array}$ \\
\hline \multicolumn{7}{|c|}{ Panel A: 1983 - 2006} \\
\hline Illiq & $\begin{array}{l}0.374 \\
(3.96)\end{array}$ & $\begin{array}{l}0.220 \\
(2.44)\end{array}$ & $\begin{array}{c}0.153 \\
(9.95)\end{array}$ & $\begin{array}{c}0.405 \\
(4.53)\end{array}$ & $\begin{array}{l}0.340 \\
(4.11)\end{array}$ & $\begin{array}{l}0.065 \\
(3.09)\end{array}$ \\
\hline$\beta_{r m}$ & $\begin{array}{l}-0.317 \\
(-0.47)\end{array}$ & $\begin{array}{l}-0.611 \\
(-0.94)\end{array}$ & $\begin{array}{l}0.294 \\
(4.41)\end{array}$ & $\begin{array}{c}0.563 \\
(1.02)\end{array}$ & $\begin{array}{c}0.140 \\
(0.28)\end{array}$ & $\begin{array}{c}0.422 \\
(4.04)\end{array}$ \\
\hline$\beta_{z u}$ & $\begin{array}{l}- \\
-\end{array}$ & $\begin{array}{l}- \\
-\end{array}$ & $\begin{array}{l}- \\
-\end{array}$ & $\begin{array}{c}0.038 \\
(0.79)\end{array}$ & $\begin{array}{l}-0.007 \\
(-0.16)\end{array}$ & $\begin{array}{l}0.045 \\
(3.11)\end{array}$ \\
\hline$\beta_{s m b}$ & - & - & - & $\begin{array}{l}-0.104 \\
(-0.37)\end{array}$ & $\begin{array}{l}-0.033 \\
(-0.12)\end{array}$ & $\begin{array}{l}-0.071 \\
(-1.09)\end{array}$ \\
\hline$\beta_{h m l}$ & - & - & - & $\begin{array}{c}0.555 \\
(1.82)\end{array}$ & $\begin{array}{c}0.413 \\
(1.43)\end{array}$ & $\begin{array}{l}0.141 \\
(3.31)\end{array}$ \\
\hline Logcap & - & - & $\begin{array}{l}- \\
- \\
\end{array}$ & $\begin{array}{c}0.013 \\
(0.12) \\
\end{array}$ & $\begin{array}{l}0.105 \\
(1.12)\end{array}$ & $\begin{array}{l}-0.091 \\
(-4.66) \\
\end{array}$ \\
\hline \multicolumn{7}{|c|}{ Panel B: 1983 - 2000} \\
\hline Illiq & $\begin{array}{l}0.353 \\
(2.98)\end{array}$ & $\begin{array}{l}0.179 \\
(1.59)\end{array}$ & $\begin{array}{c}0.174 \\
(9.23)\end{array}$ & $\begin{array}{c}0.501 \\
(4.86)\end{array}$ & $\begin{array}{l}0.423 \\
(4.55)\end{array}$ & $\begin{array}{c}0.078 \\
(3.03)\end{array}$ \\
\hline$\beta_{r m}$ & $\begin{array}{l}-0.114 \\
(-0.19)\end{array}$ & $\begin{array}{l}-0.336 \\
(-0.56)\end{array}$ & $\begin{array}{l}0.221 \\
(4.38)\end{array}$ & $\begin{array}{l}0.261 \\
(0.45)\end{array}$ & $\begin{array}{l}-0.141 \\
(-0.28)\end{array}$ & $\begin{array}{c}0.402 \\
(3.11)\end{array}$ \\
\hline$\beta_{z u}$ & $\begin{array}{l}- \\
-\end{array}$ & $\begin{array}{l}- \\
-\end{array}$ & $\begin{array}{l}- \\
-\end{array}$ & $\begin{array}{c}0.089 \\
(1.50)\end{array}$ & $\begin{array}{l}0.029 \\
(0.55)\end{array}$ & $\begin{array}{c}0.060 \\
(3.42)\end{array}$ \\
\hline$\beta_{s m b}$ & - & - & - & $\begin{array}{l}-0.125 \\
(-0.35)\end{array}$ & $\begin{array}{l}-0.003 \\
(-0.01)\end{array}$ & $\begin{array}{l}-0.122 \\
(-1.47)\end{array}$ \\
\hline$\beta_{h m l}$ & - & - & - & $\begin{array}{c}0.434 \\
(1.44)\end{array}$ & $\begin{array}{c}0.260 \\
(0.90)\end{array}$ & $\begin{array}{c}0.174 \\
(3.46)\end{array}$ \\
\hline Logcap & - & - & $\begin{array}{l}- \\
-\end{array}$ & $\begin{array}{c}0.163 \\
(1.45)\end{array}$ & $\begin{array}{c}0.262 \\
(2.83)\end{array}$ & $\begin{array}{l}-0.098 \\
(-4.54)\end{array}$ \\
\hline & & Pane & C: 200 & 2006 & & \\
\hline Illiq & $\begin{array}{c}0.431 \\
(3.17)\end{array}$ & $\begin{array}{l}0.335 \\
(2.57)\end{array}$ & $\begin{array}{c}0.096 \\
(3.91)\end{array}$ & $\begin{array}{c}0.134 \\
(0.62)\end{array}$ & $\begin{array}{l}0.105 \\
(0.54)\end{array}$ & $\begin{array}{c}0.028 \\
(0.82)\end{array}$ \\
\hline$\beta_{r m}$ & $\begin{array}{l}-0.894 \\
(-0.46)\end{array}$ & $\begin{array}{l}-1.393 \\
(-0.74)\end{array}$ & $\begin{array}{l}0.498 \\
(2.37)\end{array}$ & $\begin{array}{l}1.420 \\
(0.92)\end{array}$ & $\begin{array}{l}0.939 \\
(0.65)\end{array}$ & $\begin{array}{c}0.480 \\
(2.89)\end{array}$ \\
\hline$\beta_{z u}$ & $\begin{array}{l}- \\
-\end{array}$ & $\begin{array}{l}- \\
-\end{array}$ & $\begin{array}{l}- \\
-\end{array}$ & $\begin{array}{l}-0.107 \\
(-1.17)\end{array}$ & $\begin{array}{l}-0.112 \\
(-1.26)\end{array}$ & $\begin{array}{c}0.004 \\
(0.19)\end{array}$ \\
\hline$\beta_{s m b}$ & - & - & - & $\begin{array}{l}-0.044 \\
(-0.09)\end{array}$ & $\begin{array}{l}-0.118 \\
(-0.27)\end{array}$ & $\begin{array}{c}0.074 \\
(0.94)\end{array}$ \\
\hline$\beta_{h m l}$ & - & - & $\begin{array}{l}- \\
-\end{array}$ & $\begin{array}{c}0.895 \\
(1.01)\end{array}$ & $\begin{array}{c}0.845 \\
(1.02)\end{array}$ & $\begin{array}{c}0.049 \\
(0.62)\end{array}$ \\
\hline Logcap & - & $\begin{array}{l}- \\
-\end{array}$ & $\begin{array}{l}- \\
-\end{array}$ & $\begin{array}{l}-0.410 \\
(-1.29)\end{array}$ & $\begin{array}{l}-0.337 \\
(-1.25)\end{array}$ & $\begin{array}{l}-0.073 \\
(-1.65)\end{array}$ \\
\hline
\end{tabular}

